\title{
Imaging techniques in the study of fossil spiders
}

Paul A. Selden, a,b, , David Penney ${ }^{\mathrm{c}}$

Keywords:

amber, Araneae, Cenozoic, CT scanning, macrophotography, Mesozoic, palaeontology, Palaeozoic, photomicrography, SEM, synchrotron 


\section{A B S T R A C T}

Spiders are the most diverse and important terrestrial predators in modern ecosystems. Therefore, fossil spiders are fundamental to understanding past terrestrial ecosystems, especially coevolution with their principal prey, the insects. Being generally soft bodied, spiders have a poor fossil record, but where they do occur, it is in the exceptional circumstance of a FossilLagerstätte. By far the greatest number of fossil spider specimens are found in amber (fossilized tree resin), but earlier than the Cretaceous and outside of amber forest areas, rock-matrix preservation is essential for the spider fossil record. Every taphonomic situation requires a special technique for study. Here, we review imaging techniques in the study of fossil spiders. The earliest depictions of fossil spiders are drawings made with the unaided eye. Light microscopy enabled detailed drawings to be produced and, later, photographs of fossil spiders appeared in the literature. In the 21 st century, digital photography has revolutionized image capture and reproduction, and scanning electron microscopy has been applied recently to fossil spiders. The most exciting modern technique, x-ray (including synchrotron source) CT scanning, is now producing extraordinary images of three-dimensional fossil spiders embedded in amber, and the method is also applicable to rock-matrix preservation. We expect to see considerable refinement of these techniques in the future, as well as the possibility of novel ones. Thanks to the excellent preservation of some fossil spiders, and modern techniques available to provide exquisite images of fine morphological details, fossil spiders can now be considered taxonomically (sub)equal to modern forms. Hence, the usual excuse for excluding fossil spiders 
in phylogenetic and other studies no longer carries as much weight as it once did, and we encourage neontologists to consider the fossil record whenever possible.

\section{Introduction}

Spiders (Araneae) occur in nearly every terrestrial ecosystem (and in some aquatic ones) and are distributed across all continents except Antarctica; dispersal by silken threads (ballooning) means that spiders may be found among the aerial plankton. Unique characteristics of the order include the possession of a venom system to assist in prey capture, and the production and utilization silk in many more ways than any other animal. Araneae is the most diverse animal group in modern terrestrial ecosystems after the five largest insect orders and mites, with 46,058 extant species in 3988 genera and 114 families (World Spider Catalog, 2016). Spiders are the most abundant predators on land today, and they have evolved many different modes of life to enable them to pursue their insect prey in all ecological niches. These include orb-, sheet- and other web weavers, sit-and-wait predators, cursorial hunters, jumping spiders, burrowers, and aquatic spiders.

The oldest spider fossils date back to the late Palaeozoic era (Selden et al., 2014), but their close relatives such as the arachnid order Uraraneida Selden, Shear \& Sutton, 2008 and the enigmatic Idmonarachne Garwood et al., 2016, were part of the first wave of terrestrialization by animals in mid-Palaeozoic times. The most primitive spider suborder, Mesothelae Pocock, 1892, had evolved by the late Palaeozoic (Selden, 1996a,b; Dunlop et al., 2016), but the other spider suborder, Opisthothelae Pocock, 1892, did not appear until the Triassic Period, including both infraorders: Mygalomorphae Pocock, 1892 (Selden \& Gall, 1992; Dalla Vecchia \& Selden, 2013) and Araneomorphae Smith, 1902 (Selden et al., 1999). Spider fossils become increasingly more 
common as we move up into Jurassic and Cretaceous strata, with spiders in amber appearing in the early Cretaceous (Penney \& Selden, 2011). Spiders appear not to have reduced in biodiversity across the K-Pg extinction event (Penney et al., 2003), but by the time of the first abundant amber deposits in the Eocene, many modern families appear which were absent in the Mesozoic, e.g. Thomisidae and Salticidae (Penney \& Selden, 2011), so that most Cenozoic spider biotas resemble their modern counterparts in similar habitats.

Spiders are rarely preserved in the fossil record because of their fragility and soft-bodied nature. Thus, fossil spiders define the existence of a Fossil-Lagerstätte (an exceptional occurrence of well-preserved fossil biota). Probably the most famous of all Fossil-Lagerstätten is amber, fossilized tree resin, which has preserved the majority of fossil spiders described to date (Penney et al., 2012a). In non-amber Fossil-Lagerstätten where spider fossils do occur, they are usually allochthonous, i.e., they are preserved out of the context of the environment in which they originally lived (though there are exceptions, such as fossils of aquatic spiders). This has a great bearing on the interpretation of these assemblages of fossils as once living communities. From the Jurassic and earlier, fossils in rocks represent our sole source of spider palaeontological data. When a layered rock is split open to reveal a fossil, you are left with two halves: part and counterpart which, at first glance, appear as mirror images of one another, but each may yield different clues to the identity of the spider. There are nearly as many different preservational styles (see Taphonomy) as there are spider-yielding Lagerstätten. Commonly, the preservation of these fossils is much poorer than those in amber, making their interpretation considerably more difficult, but fine detail of external and internal structures can be preserved. By far the commonest sources of fossilized spiders are as inclusions in amber, where the degree of 
preservation can be quite exceptional, and references to amber spiders date back to the early 1700s (Kundmann, 1737; Sendel, 1742) for fossils in Baltic amber. Amber is the fossilized form of tree resin and has properties similar to amorphous polymeric glass. The oldest amber that contains fossil spiders is from the Lower Cretaceous (130 Ma) of Lebanon (and Jordan), and various deposits (including sub-fossil resin, commonly termed copal) from around the world fill in the gaps from then until the present (Penney, 2010a). For extensive reviews of the spider fossil record see Selden \& Penney (2010) and Penney \& Selden (2011).

The goals of the palaeoarachnologist are to extract as much information as is preserved in the fossil, in order to discover as much as possible about its identity and palaeobiology, and to disseminate this knowledge through publication, including illustrations. In this review, we look at the history of illustration of fossil spiders, give a survey of the range of techniques used in the study of fossil spiders, and present numerous studies which illustrate how the improvement of imaging techniques in the last few decades have greatly enhanced our knowledge of fossil spiders and their phylogeny.

\section{Taphonomy}

\subsection{Amber}

The most prolific Fossil-Lagerstätte bearing spiders is amber, the highly polymerized form of fossil tree resin, where they usually represent 1.0-5.9\% (3.2 \pm 1.25$)$ (Penney \& Selden, 2011: table 6) of all inclusions, and in this mode of preservation they are usually autocthonous. Living animals become trapped in the sticky resin when it is exuded by the tree, and subsequently 
covered by more resin (e.g. Penney 2002), or become engulfed in less viscous, rapid-flowing exudates (Penney, 2005).

Reasons for trees to exude resin in copious quantities are not well known (reasons proposed to date include disease, wound repair, and defense against herbivory, to name a few), but many insects, and therefore their predators, are attracted to resin seeps. The resin hardens in contact with the air and, following burial in sediment over millions of years, diagenetic processes turn the resin into the fossilized product amber. Semi-fossilized resin is softer and is termed copal; it is also an excellent source of preserved spiders (e.g. Penney et al., 2012b), most often belonging to extant species. Amber preserves fossil inclusions through a process similar to mummification by a combination of rapid and thorough fixation, dehydration and the antibiotic properties of the resin (Henwood, 1993). The degree of preservation is exquisite, and includes fine detail of tissues, cells, and cellular ultrastructure with a startlingly life-like fidelity, as revealed by scanning (SEM) and transmission (TEM) electron microscopy (Grimaldi et al., 1994), detailed for a Baltic amber spider by SEM by Mierzejewski (1976a). It is evident from numerous amber inclusion assemblages that they represent the remains of warm-temperate to tropical forests. The climate and soil type of similar present-day ecosystems provide poor opportunities for fossilization, yet they contain more than half of the terrestrial species in the world. When one considers the current rate of demise of these forests through anthropogenic factors, the value of fossil amber inclusions for investigating historical ecological changes, and thus possible future consequences of modern deforestation, becomes immediately apparent.

There are approximately 200 known amber deposits around the world (Martínez-Delclòs et al., 2004), but relatively few have produced abundant biological inclusions, and those that do 
occur mainly in strata of Neogene, Paleogene, or Cretaceous age. A notable exception is the recent discovery of a few fossil inclusions (Acari and Diptera) in amber of Triassic age from northern Italy (Schmidt et al., 2012; Sidorchuk et al., 2014). Interestingly, no arthropod inclusions have been found in amber of Jurassic age, despite the existence of numerous deposits in close proximity to rich inclusion-bearing Cretaceous deposits, e.g. in Lebanon (Nohra et al., 2013).

The best-known deposits preserving a diverse assemblage of fossils spiders are from the Eocene of the Baltic region (Wunderlich, 2004), the Miocene of the Dominican Republic (Penney, 2008), and the Cretaceous of Myanmar (Wunderlich, 2015). Selden \& Penney (2010) provided an extensive list of the other spider-bearing deposits and the families recorded, and Penney (2010a) covered the geological setting, botanical origins and diversity of inclusions from the various major world amber deposits. However, new discoveries of fossiliferous amber deposits occur on a reasonably frequent basis. Important finds in recent years include the first deposits from Australia (Hand et al., 2010), India (Rust et al., 2010) and New Zealand (Kaulfuss et al., 2013, 2016), all of Neogene or Paleogene age, and new Cretaceous deposits from Ethiopia (Schmidt et al., 2010 - now thought to be Cenozoic see Perrichot et al., 2016) and CongoBrazzaville (Perrichot et al., 2016). Important new fossiliferous outcrops have also been discovered from the Cretaceous of Lebanon, Spain, and France. The discovery of a new fossiliferous deposit is significant because it presents the opportunity to conduct a quantitative investigation prior to commercial development or selective collecting of the fossil inclusions. Unfortunately, many newly discovered amber deposits are only available for exploitation for a short period, for example as a result of being noticed during excavations for new roads, 
buildings, etc. (e.g. Vendean amber from northwest France, see Perrichot \& Néreaudeau, 2014).

One must wonder how many such deposits become exposed without ever having their palaeontological significance realized before they are filled in again and lost to contemporary science (Penney, 2016).

Just a single species (Diptera) has been described from the Australian Cape York amber, though a diverse assemblage including spiders has been noted (Hand et al., 2010). Early reports (based on FTIR analysis) proposed that the Cape York amber originated from Araucariaceae (Agathis sp.) trees on the Australian mainland, was washed out to sea during monsoon rains and was subsequently re-deposited along the high tide mark by local coastal currents and waves. However, a recent study by Sonibare et al. (2014) used pyrolysis-gas chromatography-mass spectrometry (Py-GC-MS) to investigate the terpenoid composition of this fossil resin, which was found to be similar to those reported in many Dipterocarpaceae resins from the floristic province of Malesia, which encompasses a region approximately between India and New Guinea. Hence, these authors proposed that the fossil resin is not indigenous to the Australian mainland and that it originated from southeast Asia. It can be expected that further research on the inclusions will shed additional light on this interesting issue.

The most recently discovered fossiliferous deposits are from New Zealand (Kaulfuss et al., 2013) and Africa (Congo-Brazzaville) (Perrichot et al., 2016). The New Zealand amber is found in various localities on South Island and is still in the very early stages of study. The amber is of Cenozoic age (Miocene) and several insect orders (and arachnids: mites, spiders and pseudoscorpions) have been discovered (Kaulfuss et al., 2013, 2016). The Early Cretaceous (Aptian, 113-117 Ma) amber of Congo-Brazzaville contains diverse inclusions of arthropods and 
plants, as observed in translucent samples, although much of the material is too opaque to be studied using conventional microscopy (Perrichot et al., 2016).

The Paleogene Indian and French (Oise) deposits are both Paleocene in age so have the potential to yield insights into faunas immediately following the end-Cretaceous extinction event. There are certainly some significant differences between the younger Baltic and slightly older Oise amber deposits. For example, jumping spiders (Salticidae) are common in the former but are absent in the latter (Penney, 2007). This is significant given that salticids are the most diverse spider family on the planet today, are the second most common spider family in Cenozoic (especially Neogene) ambers, but are unknown from Cretaceous amber faunas (Penney, 2010b). Note that the Sakhalin Island (Russian Far East) amber previously thought to be of Paleocene age (e.g. Zherikhin \& Eskov, 1999) is now considered to be Middle Eocene (Baranov et al., 2014).

Inclusions in Ethiopian amber (now considered to be Cenozoic, see Perrichot et al., 2016) include a diverse assemblage of arthropods. Wunderlich (2015) questioned the Mesozoic age of this deposit based on the presence of a well preserved male Linyphiidae spider, which has not yet been formally described but was figured by Schmidt et al. (2010).

\subsection{Rock matrix preservation}

Much more rarely than in amber, fossil spiders are preserved in sedimentary rocks. There are nearly as many different preservational styles as there are occurrences of this form of preservation. A number of Mesozoic spider occurrences are in Plattenkalk (lithographic limestone): thinly bedded, fine-grained limestones usually deposited in still water by settling of calcium carbonate grains. The best-known example of Plattenkalk in the fossil record is the 
Altmühltal Formation (Solnhofen Limestone) of southern Germany, but this deposit is marine in origin and includes no spiders. The early Cretaceous Plattenkalk from Crato, Brazil (Martill, 1993; Mesquita, 1996; Selden et al., 2002, 2006; Dunlop et al., 2007) preserves spiders (as well as a wealth of insects and other organisms) by replacement with goethite (iron hydroxide) within the limestone (Fig. 1) (Barling et al., 2015). This is unusual, however, and in most lagoonal and lacustrine limestones the organisms are preserved as organic fragments. The main organic constituents of arthropod cuticle are the polysaccharide chitin linked to the protein arthropodin. Taphonomic processes usually result in random depolymerization of the chitin-arthropodin chains to a substance akin to kerogen, although evidence of original chitin is occasionally discovered geochemically (Briggs et al., 1998; Stankiewicz et al., 2000; Gupta et al., 2010; Cody et al., 2011). A number of fossil and sub-fossil spiders preserved as little-altered organic matter are known from late Neogene and younger deposits, including a range of sub-fossil spider fragments from Holocene peats in Cheshire, UK (Scott, 2003), a thomisid carapace from kettlehole copropelic sediments dated at $6000 \pm 2000 \mathrm{BP}$ from Wyoming (Cutler, 1970), a prosoma of an Erigone sp. from pond silts dating from an interstadial within the Wisconsin glaciation in Alaska (Hopkins, Giterman \& Matthews, 1976), specimens in the Quaternary diatomite of Italy (Bottali, 1975), and in late Pliocene sink-hole lake of Willershausen, Germany (Schawaller, 1982). Examples of older Lagerstätten with spiders preserved as organic matter in fluvial, lagoonal, or lacustrine settings include a single male palp of a thomisid from late Miocene fluvial sediments beneath a lava flow in Alaska (Leech \& Matthews, 1971), the Miocene of Germany (Bertkau, 1878a; Heyden, 1859; Schawaller \& Ono, 1979; Wunderlich, 1985), Switzerland (Heer, 1865, 1872, 1876), and Shanwang, China (Hong, 1985; Zhang, Sun \& Zhang, 1994); the 
Eocene of Germany (Wunderlich, 1986), Florissant and Green River, USA (Licht, 1986; Selden \& Wang, 2014), and British Columbia, Canada (Selden \& Penney, 2009); the early Cretaceous of El Montsec and Las Hoyas, Spain (Selden, 1989, 1990, 1991a,b, 2014a; Selden \& Penney, 2003), Siberia and Mongolia (Eskov \& Zonstein, 1990), Victoria, Australia (Jell \& Duncan, 1986), Mexico (Feldmann et al., 1998), and north-east China (Selden, Ren \& Shih, 2016); the Jurassic of Transbaikalia and Kazakhstan (Eskov, 1984, 1987; Selden, 2012), and north-east China (Selden, Huang \& Ren, 2008; Selden \& Huang, 2010; Selden, Shih \& Ren, 2011; Selden, Ren \& Shih, 2016); the Triassic of France (Selden \& Gall, 1992), South Africa (Selden et al., 1999; Selden, Anderson \& Anderson, 2009) and Italy (Dalla Vecchia \& Selden, 2013); the Permian of the Ural Mountains, Russia (Eskov \& Selden, 2005); and the late Devonian of Gilboa, New York (Selden, Shear \& Bonamo, 1991). The Palaeozoic occurrences are of uraraneids, which were originally described as spiders but now form their own arachnid order (Selden, Shear \& Sutton, 2008b).

More unusual types of preservation include the Bembridge Marls Insect Bed, Eocene of the Isle of Wight, England, in which the spider fossils occur as external moulds with calcite replacement of internal structures such as muscles and respiratory organs (Selden, 2001, 2002, 2014b). A somewhat similar example of preservation in a calcitic matrix is seen in the Lower Jurassic locality at Grimmen, Germany where there are internal moulds in calcite in addition to external moulds with some organic material (Selden \& Dunlop, 2014). Fossil spiders from Carboniferous Coal Measures of Europe and North America are generally preserved as external moulds, sometimes infilled with kaolinite, in clay ironstone concretions, for example at Mazon Creek, Illinois (Baird et al., 1986). A most peculiar preservation - replacement by silica within 
calcareous nodules - occurs in the Miocene Barstow Formation of California (Palmer, 1957). Another case of unusual preservation is that of the Jurassic Talbragar Fish Bed in New South Wales, Australia, where spiders are preserved as internal moulds of opaline silica within red tuffaceous siltstone (Selden \& Beattie, 2013). Coal Measures spiders from Nýřany, Czech Republic, e.g. Pyritaranea tubifera Frič, 1901, are poorly preserved as pyrite replacement in organic black shale, and a similar pyrite replacement can be seen in the Miocene Foulden Maar locality of New Zealand (Kaulfuss et al., 2014). In the Triassic Solite deposits of Virginia, USA, the spiders are preserved as silver flakes in a black matrix (Selden et al., 1999), and the preservation of the arthropods in the Korean Cretaceous Jinju Formation (Selden et al., 2012) is remarkably similar.

\section{Preparation Methods}

Each preservational style demands its own method of preparation for study. Raw amber can be cut, ground, and polished, and viewed directly under a microscope using incident and transmitted light, or smaller pieces can be set in a clear plastic resin prior to grinding for ease of manipulation. Oddly shaped amber pieces can be immersed in mineral oil, which has the same refractive index as amber, to facilitate microscopy by preventing unwanted light reflection and refraction. Indian (Cambay) amber can be dissolved using orange oil in order to extract the fossilized inclusions (Mazur et al., 2014; see also Azar, 1997; Penney et al., 2013, who did the same [using different solvents] with Lebanese amber and Colombian copal respectively), but this is not standard practice, and inclusions in most ambers would most likely be destroyed by this process. A fully referenced discussion of methods for amber preparation is given in Penney (2008). In addition, Sidorchuk (2013) developed a new technique for the preparation of tiny 
pieces of amber, particularly suited to her study of mites, but equally applicable for other small arthropods.

It is unfortunate that, given the vibrant amber market and the high prices private collectors are willing to pay, forgeries abound, and specimens often get mixed up, making provenance and age difficult to ascertain without employing rigorous tests. Forgeries vary from the making of curios by embedding natural history specimens in Kauri gum (see fig. 5a in Grimaldi et al., 1994), through accidental or deliberate mixing of ambers and/or copals from different provenances, to elaborate forgeries involving inserting modern specimens into resin-bearing cavities inside real amber (e.g. Ross, 1998). Tests are available to detect real amber, and range from simple examination of other inclusions (e.g. oak stellate hairs and coatings of white emulsion are common in Baltic amber) to more sophisticated techniques such as infra-red spectroscopy, pyrolysis gas chromatography and mass spectroscopy for determining chemical signatures (Grimaldi et al., 1994). However, the excavations of many recently discovered amber deposits (e.g. New Jersey, Spanish, Lebanese, French Eocene and Cretaceous, to mention but a few) have been organized by recognized experts in established museums and there is usually no need to question the authenticity of specimens from these sources. There are also Dominican amber fossil dealers who extract directly from the mines and prepare their own material, so this too is unlikely to be contaminated with fakes. Some of the older museum collections would certainly benefit from individual assessment of samples for authenticity, but this would presumably be a time-consuming, costly and laborious exercise, not to mention a potentially embarrassing one. 
Removal of hard matrices necessitates the use mounted needles and small chisels, e.g. the Jurassic tuffaceous sediments form China: Selden, Huang \& Ren, 2008; Selden \& Huang, 2010; Selden, Shih \& Ren, 2011, Selden, Ren \& Shih, 2016; whereas soft matrices, e.g. in Plattenkalk preservation and to clear kaolinite from ironstone nodules, can be removed using an aeroneedle (Selden, 2003). Working with this device under a binocular microscope, dislodged debris is gently blown clear of the working site. In some instances, gentle dissolution of recalcitrant calcite can be achieved with dilute hydrochloric acid, with great care. To remove the tiny fossils from Devonian clayrocks of New York, hydrofluoric acid was used to macerate the sediment (e.g. Shear et al., 1987; Selden, Shear \& Bonamo, 1991), and the resultant organic fragments sorted in water under the stereomicroscope.

\section{History of Imaging of Fossil Spiders}

Spiders have been familiar animals to human cultures since Man first recorded his observations of the natural world. There are drawings of spiders on the walls of caves (Hillyard 1994; Leroy \& Leroy 2003) and spiders crop up in the mythology of many human societies, commonly as symbols of danger or of clever handiwork (Gertsch 1949; Cloudsley-Thompson 2001). The first fossil spider mentioned in the literature is by Breynio (1726), who described a fern leaf preserved in amber and mentioned, in passing, a spider and a fly in the same piece; the figure does not show the spider. In Edward Lhwyd's Lithophylacii Britannici Ichnographia (Lhwyd 1699), spiders are illustrated on plate 4, but the two specimens shown, together with two insects, are on a plate of Carboniferous seed-ferns entitled 'Lithophyta'. The arthropods are neither numbered nor mentioned in the plate legend or text, and appear to be merely decorations rather than illustrations of real fossils (Roemer, 1866). As far as we are aware, the earliest printed 
illustration of a real fossil spider was that by Kundmann (1737), whose plate XII, fig. 13 (reproduced here in Fig. 2A) depicts a spider in a an amber pendant. The illustration lies alongside fig. 14, which shows a slab of Solnhofen Limestone with Spinnensteine: 'stone spiders' which are actually the remains of the stemless crinoid Saccocoma. Sendel (1742) described many spiders in amber, and illustrated them on his plate V. Some can be identified as jumping spiders (Salticidae; Wichard \& Greven, 2009), and pl. V, fig. 12 depicts a spider in an orb web.

The earliest fossil spider to be described following the publication of the tenth edition of Linnaeus's 1758 Systema Naturae (which incorporated binomials used by Clerck in his 1757 work on Swedish spiders Svenska spindlar (Araneae suecici) and attributed to him) is Aranea fusca pilosa Bloch, 1776. Bloch (1776) illustrated a number of fossil spiders and other animal inclusions in copal; the spider pictures are reproduced in Dunlop \& Jekel (2008, fig. 1). The illustrations show rather generic blobs with appendages in pieces of copal which, because of the mention in the description of white slime around the specimen (which is common in Baltic amber inclusions), it is likely this was true amber. The specimens are now lost and the illustration of Aranea fusca pilosa (Bloch, 1776, pl. III, fig. 2) is insufficient to identify even as a spider, so the name is a nomen dubium (Dunlop \& Jekel, 2008). Bloch's (1776) plate III, figure 5 (reproduced in Dunlop \& Jekel, 2008, fig. 1b), however, is clearly a spider, which Bloch named simply Aranea, although it looks more like a ground spider than an orb-weaver of the genus Araneus. These 18th century illustrations pre-dated lithography (Senefelder, 1821), so were mostly printed by copper plate engraving and, where necessary, coloured by hand (e.g. Bloch, 1776). 
Schweigger (1819, pl. VIII, fig. 68) illustrated a beautiful specimen of a spider in either amber or copal. Since August Schweigger (1783-1821) was professor of medicine and botany in Königsberg (now Kaliningrad, Russia) on the Baltic Sea, it is most likely that the figured specimen is in Baltic amber; however, it is now presumed lost (Dunlop \& Penney, 2009). The specimen figured and described was not named by Schweigger, but by Holl (1829) in his textbook Handbuch der Petrefactenkunde, as Entomocephalus formicoides, who considered it to show a transition from spiders to ants. Judging from Schweigger's illustration and description, it is almost certainly an ant-mimicking spider of the genus Myrmarachne MacLeay, 1839; in which case Entomocephalus Holl, 1829 would be the senior subjective synonym of the genus, and the widely used Myrmarachne should be subsumed within Entomocephalus. For this reason, Dunlop \& Penney (2009) proposed that the genus name Entomocephalus be suppressed, since it has had little usage in the literature, and this proposal was accepted by the International Commission on Zoological Nomenclature (ICZN, 2010). Schweigger's plates are hand-colored copper plates.

By the early 19th Century, spiders were being mentioned from the Miocene of Aix en Provence (Serres 1828, 1829). Buckland (1837) figured a spider from this locality, and this specimen (BMNH In 43302 in the Natural History Museum, London) was eventually named as Theridium bucklandii (=Theridion bucklandi) by Thorell (1870). It was the first recognizable non-amber spider to be illustrated in the literature, and is shown here in Fig. 3.

Fig. 4 shows a graph of the number of fossil spider species formally described per year from 1800 to the present day, as well as some noteworthy events described here. It can be seen that the record is dominated by spiders preserved in amber, and by particular monographic works, especially those of Koch \& Berendt (1854) and, in recent years, Wunderlich (1988, 2004, 2008, 
2015). In their monograph on Baltic amber spiders, Koch \& Berendt (1854, published posthumously with footnotes by Menge) provided a series of plates of how they envisaged the spiders would have looked in life, i.e. they were not drawn in the positions in which they were preserved in the amber. Apart from the Archaeidae (a unique spider family in that it was first described from fossils before being discovered in the extant fauna several decades later), it would be impossible to use the majority of illustrations to identify the spider inclusions because they all resemble generic spiders, with no attention to additional diagnostic detail, apart from eye arrangements in some instances.

Elvina antiqua (von Heyden, 1859) and Gea krantzi von Heyden, 1859 (BMNH 58824 and 58825 respectively, in the Natural History Museum, London), from the Miocene Brown Coal of Grube Stoschen, near Linz am Rhein, Germany, were the first non-amber fossil spiders to be formally described, illustrated, and named simultaneously (von Heyden, 1859). Other early descriptions and illustrations of Miocene fossil spiders were by Heer (1865), who described 28 specimens belonging to 10 genera, 11 of which were illustrated, from the lacustrine deposits of Oeningen, on the Swiss/German border, and Bertkau (1878) studied the fossil spider fauna from the Brown Coal of Rott, Germany, describing and illustrating seven spiders and a millipede. Philipp Bertkau (1849-1894) produced several pioneering works on the anatomy and physiology of spiders, so he used microscopy extensively in his studies. His illustrations of the fossil spiders were the first to show detailed body parts at higher magnification.

The first fossil spider to be formally described from Palaeozoic strata, Protolycosa anthracophila Roemer, 1866, from the Coal Measures of Katowice, Poland, was apparently lost during World War II, but the specimen described by Harger (1874), from the famous 
Carboniferous Mazon Creek locality, Illinois, as Arthrolycosa antiqua Harger, 1874 remains in the collections of the Peabody Museum, Yale University (YPM 161). Harger described the fossil as having a segmented opisthosoma, and compared it to the primitive living Liphistius Schiodte, 1849. Illustrations of fossil spiders in the 19th century were all drawings, even though photography was becoming more widespread in scientific research. For example, illustrations of the Cenozoic spiders of the United States by Scudder (1890) were drawings (Fig. 2B).

The earliest photographs of fossil spiders were published by Petrunkevitch (1913) in his monograph on North American Palaeozoic Arachnida. These Palaeozoic specimens are preserved in the rock matrix, but the first amber spiders to be described and illustrated by photography did not appear until nearly thirty years later, in Petrunkevitch's (1942) first revision of Koch \& Berendt's (1854) and Menge's $(1854,1856)$ Baltic amber specimens. In this work, Petrunkevitch (1942: 139-140) gave a detailed description of the methods he used to photograph the specimens in amber. The specimens were fully immersed in cedar oil (presumably to prevent stray lighting artifacts from the surface of the amber piece); he tilted the dish, and sometimes used a strip of glass immersed with the specimen, in order to get the correct angle of view. This set-up was placed on a sheet of transparent glass on top of either a sheet of white glass or a piece of black velvet, in order to obtain some lighting from behind or a dark field, respectively. Lighting was achieved with a pair of lamps placed at about $45^{\circ}$ from the specimen. Filters, either deep yellow or infra-red, were used, depending on the colour of the amber, and the lens was stopped down to $\mathrm{f} / 16$ or $\mathrm{f} / 22$ (after careful focussing) to obtain the greatest depth of field. Photographs of both amber and (a single) matrix-preserved fossil spider appeared in Petrunkevitch's (1946) paper on fossil spiders in the collection of the American Museum of Natural History, but it was not until 
Petrunkevitch's (1950) work on Baltic amber spiders in the Museum of Comparative Zoology that photographs of fossil spiders obviously taken down the microscope (photomicrographs) were first published.

Petrunkevitch (1949: 113-114) gave details about his methods of photographing Palaeozoic fossil arachnids preserved in the rock. These are mostly found in clay-ironstone nodules, such as those from Mazon Creek, Illinois, and are mainly external moulds. A typical workflow for this kind of fossil would be to coat the surface with a white substance, such as ammonium chloride sublimate, and then to use low-angle illumination to obtain the greatest relief on the specimen. However, Petrunkevitch shunned the use of coatings because they mask colour differences, which may be the only indication of some morphological features. Instead, Petrunkevitch photographed the natural rock surface, varying the illumination as required. He used two or three lamps with condensers, and sometimes ground glass diffusers, to obtain the required illumination. As with the amber specimens, Petrunkevitch achieved the best depth of field with apertures of $\mathrm{f} / 16$ or $\mathrm{f} / 22$. Interestingly, in Petrunkevitch's (1953) study of the Palaeozoic and Mesozoic arachnids of Europe, he provided both drawings and photographs but, in his 1958 study of amber spiders in European collections, he decided to eschew photography and gave only camera lucida drawings, on the basis that it is much quicker, so he could examine all of the specimens in the collections in London, Paris, Copenhagen, and Berlin during a time-limited visit to Europe (Petrunkevitch, 1958: 101-103).

\section{Macrophotography and Photomicrography}

The characters used to differentiate spider taxa are somewhat dependent on the rank of the organisms being compared. For example, at the species level, genitalic characters are of the 
utmost importance; these can be commonly be quite subtle, and require a great deal of manipulation of the specimen under the stereomicroscope in order to compare specimens with published illustrations in a similar orientation. Characters at the generic level are generally based on more obvious genitalic or somatic characters. From early in the study of spider systematics, it became clear that certain characters are especially important for separating families and higherlevel taxa of spiders. These include the number and relative position of the eyes, the presence or absence of a cribellum and its associated calamistrum, the number of tarsal claws, the presence/ absence of claw tufts and scopulae, the direction of movement of the fang relative to the body of the chelicera, the number of book lungs, the number of spinnerets, the number and arrangement of trichobothria on the legs, the simplicity/complexity of the genitalia, and the presence/absence of opisthosomal tergites. Some of these characters define major taxa (suborders, infraorders), while others are important at the family level. What is important when studying fossil spiders is whether any of these morphological characters are preserved and can be seen in the fossil, thus allowing it to be identified to at least family level. Much more commonly than arachnologists would like, spider families are defined on a combination of characters rather than one or more autapomorphies.

Standard binocular microscopy is sufficient to study gross morphology, and hence to identify a fossil spider to suborder and infraorder, usually to a higher-level clade such as the Haplogynae or Dionycha, and commonly to superfamily level. To observe minute details, however, such as tarsal claws or spinneret spigots, it is necessary to use higher magnifications, and this can present difficulties for the student of fossil spiders. Spiders in amber suffer from the vagaries of internal reflection of light within the amber piece, annoying gas bubbles, debris, or other inclusions in the 
line of sight of the object to be observed, and sometimes the disposition of the spider itself, e.g. the legs may be curled into the body, or the cheliceral teeth cannot be seen and the specimen cannot be manipulated as would be possible in an extant spider. Such frustrations are compounded in matrix-preserved spiders, in which morphological characters may be completely missing because of the method of preservation.

\subsection{Macrophotography}

Techniques of macrophotography have changed little over the years, but the integration of digital technology has greatly enhanced the reliability of good results. The basic technique involves mounting a camera on a copy stand with its lens pointing downwards towards the specimen which lies on the base board, or on a small laboratory scissor jack to adjust the height of the specimen. The camera (and/or its lens) is clamped to the upright of the copy stand, and is also adjustable for focussing, and either of these may be placed onto a macrophotography slider for the finest control. The lens can be mounted directly on the camera body or attached by means of a bellows. One of the best set-ups for macrophotography was the Leitz Aristophot (see: http:// microscope.database.free.fr/Accessories_manuals_files/Aristophot\%20Instructions.pdf), which was essentially a complete microphotographic system utilizing Leitz camera bodies (35 mm or large format), bellows, lenses, and an extremely sturdy copy stand; it could also be mounted on a microscope. Many are still in use. The separation of the lens from the focal plane with a bellows or extension tubes produces high magnification at a reasonable distance from the specimen; but the greater the magnification, the shallower the depth of field. Using a smaller aperture (higher $\mathrm{f}$ stop) requires brighter illumination, but results in a less sharp image overall due to diffraction. Moreover, the best resolution requires slowest film speeds, and hence long exposures (which is 
why the Aristophot needed to be so stable and vibration-free). Some modern set-ups, e.g. longdistance lenses with high-intensity flash bursts, can achieve much better depth of field using bright illumination and smaller apertures with high-resolution camera sensors (e.g. http:// www.infinity-usa.com).

The improvement in digital camera technology has revolutionized macrophotography in the last 20 years. The first widely available digital single-lens reflex (DSLR) cameras were produced as backs for existing models from Canon and Nikon, and included the Kodak DCS (Digital Camera System), later followed by integrated DSLRs from the main manufacturers, in the late 1990s. These provided a resolution of about 1-2 megapixels, and cost a great deal of money. At that time, it was considered better to shoot on low-speed (e.g. 100 ISO) film and then scan it, to get the best resolution, and for the lowest cost (e.g. Selden \& Penney, 2003). However, the 21st century saw a rapid increase in sensor resolution, so that digital photography came to be both acceptable and cost-effective for scientific imaging. Remaining problems, such as dust on the sensor, have, for the most part, been resolved; but newer ones have arisen, such as the computing power (and time) it takes to manipulate huge images captured by very large sensors. Once digital photography became usable and affordable for the scientific community, improvements in software took over as the main driving force behind innovation in fossil imaging. In particular, the use of image stacking and tiling to produce composite pictures with a large depth of field and seamless stitching together more than one part of a specimen to produce a larger image. The depth of field problem has been discussed; formerly, when assembling two or more photographs to produce a composite image of a fossil, good darkroom skills (to produce similarly exposed 
prints) and great dexterity with scissors and glue was required to produce a respectable plate (see, e.g. Shear et al., 1987, fig. 138; Selden, 1990, text-fig. 4d).

A modern macrophotography set-up for fossil spiders (Fig. 5A) consists of a DSLR camera body with a large sensor, mounted on a copy stand (with or without a macro slider for fine adjustments), a macro lens (ideally a fixed focal length lens of about 50-100 $\mathrm{mm}$ ), and a computer connection with software to control the shoot. Illumination depends on the subject. Flash lighting is bright but less easily managed than floodlighting or ring lights. Incident lighting can be moved around to provide shadows (or remove unsightly flaring) as necessary, but the subject needs to be fairly evenly illuminated to achieve a photograph with balanced exposure. Incident lighting can be as flash or constant lighting, and can involve any number of sources, even a mixture of flash and constant illumination. Ring lighting, using a flash ring or a ring light, generally attached to the lens, provides an even light, though even with these, the lighting can be turned on or off in sectors to provide some directionality.

Specimen preparation is vital to a good picture. We have already discussed the merits (or not) of whitening rock-matrix preserved spiders which have a good amount of relief with ammonium chloride sublimate (or similar). This technique requires low-angle incident light, generally from the north-west (see, e.g. Selden \& Romano, 1983, fig. 2a,c). Both coated and uncoated specimens should have at least some even illumination in addition to low-angle light, to bring out detail in the shadows, and is especially important for uncoated specimens, in which the colour differences are important. In contrast, to enhance color differences where relief is of no importance, the specimen can be immersed in a liquid such as ethanol or paraffin (compare Selden \& Romano, 1983, fig. 2a,c with fig. 2b,d, or Garwood et al., 2016, fig. 1a,b with fig. 
1c,d). Complete immersion is preferable, to provide an even surface and prevent reflections which occur when the liquid is simply run onto the specimen surface. Ethanol is preferred because it evaporates easily, leaving no deposit, though clean water can be used. The advantage of paraffin is that it does not need topping up during a long photo session, but takes a long time to drain and dry. A similar effect to liquid immersion can be achieved using polarized light. Ideally, polarizing filters are placed both on the lens and in front of the light source. These (most easily the one on the lens) should then be rotated to extinction, and the room light turned off. This has the effect of reducing glare and increasing contrast between organic matter and the rock matrix. Sometimes, simply using polarized light negates the need for immersion but, more usually, a combination of the two achieves the best results (see, e.g. figs. in Conway Morris et al., 2015). Amber is a different story. Most fossil spiders in amber are very small so photography needs to be done in conjunction with a microscope (as will be detailed in the next section), although should you wish to take macrophotographs of the inclusions without a microscope, then the same general principles apply.

\subsection{Photomicrography}

The essentials of photomicrography are much the same as for macrophotography, except that the microscope acts as the lens. Preparation of specimens (e.g. whitening, immersion in ethanol) is the same as for macrophotography, and illumination is also similar, with the exception that transmitted light is also more commonly used (for amber). In general, it is simplest to mount a DSLR onto a phototube attached to the trinocular head of a stereomicroscope (Fig. 5B). Taking pictures then follows the same procedure as with macrophotography, and a polarizing filter can be placed on the objective lens if required. The main difference from macrophotography is that 
incremental captures at different focussing levels cannot be executed in software, so must be done manually. However, some microscope manufacturers (e.g. Leica) sell camera bodies which integrate with their microscopes and capture software to produce automatic z-stacks. In general, we have found automatic capture and stacking software to produce less reliable results than manual stacking.

Amber, and other translucent specimens, can be placed on the transmitted light base of a stereomicroscope in order to get transmitted or dark field illumination. For higher magnifications, however, a compound microscope, whereby the specimen is placed on a stage with illumination from beneath via a condenser lens, may be necessary. Not only does this set-up provide a higher magnification, it also gives a greater variety of lighting techniques, such as polarization. However, the nature of high magnification means that the objective lens is generally much closer to the specimen, and for larger specimens, a large piece of amber, for example, it may not be possible to get the spider into focus. Long working distance objectives are available, however, to overcome this. Material extracted from the rock matrix from the Devonian of New York (Shear et al., 1987; Selden, Shear \& Bonamo, 1991) was mounted on slides and studied using Nomarski Interference Contrast transmitted illumination on the compound microscope (Fig. 6).

If the specimen is opaque, as in a matrix-preserved spider, then transmitted light is of no use, but incident light can be used. To get incident lighting close to the specimen when it is almost touching the objective lens is a challenge, but a reflected light microscope can overcome this. In this case, the specimen should have little relief but the use of polarized light or liquid immersion is necessary. Since the objective is very close to the specimen, use of immersion will result in 
immersing the lens, so either lenses which can be immersed should be used, or oil-immersion lenses are excellent for high magnifications. This last technique was used in the first study of the spiders from the Cretaceous of El Montsec (Selden, 1989, 1990) (Fig. 7).

The three-dimensional, matrix-entombed nature of amber-preserved specimens presents additional complications. Optical distortions are produced by irregular surfaces, and light bounces off curved surfaces at awkward angles (Fig. 8A). These problems are largely eliminated when the amber specimen is immersed in a fluid that has the same refractive index of about 1.54 $+/-0.01$ (tung oil has a refractive index of $\sim 1.529$ and works well for this purpose) (Fig. 8B). Some distortion can still be produced at the fluid surface, but this can be reduced by floating a microscope slide cover glass on it. Furthermore, the three-dimensional nature of amber inclusions can cause problems if the thickness of the specimen exceeds the depth of field. A typical zoom stereomicroscope has a depth of field varying between a few tens and few hundred micrometres, depending on the magnification. Many amber inclusions are thicker than this so they do not appear to be wholly in focus on any single photograph. Recent advances in image processing have overcome this problem. It is possible to take numerous digital images, focusing slightly further down the specimen each time to produce a stack. Software that combines the infocus parts of each image in the stack is used to produce a single image with everything in focus (see Haug et al., 2009, and later in this review) (Fig. 8B-E).

On the other hand, amber inclusions have the potential to be photographed in fine detail because they can be viewed from many directions. Good photographs depend on optimal orientation, lighting, and focus. The thinner the surrounding amber matrix the better, but it is often not possible to further prepare museum specimens by cutting them up into several different 
pieces, so often it comes down to a process of trial and error. As noted by Crighton \& Carrió (2007), when an inclusion within amber is illuminated, the whole material tends to light up with a generalized glow, making it impossible to generate a standard impression of lighting from the top left, as is standard for many palaeontology journals. Indeed, light from above will tend to be reflected off the upper surface, making fine detail less likely to be recorded. Delicate structural features, such as leg hairs, are best observed when illuminated from the side or obliquely from below. The more the light source is moved underneath the specimen, the brighter the background will glow and the better the peripheral features, though moving it too far below will provide too much light. Using a second lamp directed from above will enhance surface textures if necessary, but the illumination will need to be less intense. In addition, using different coloured backgrounds can enhance the contrast of particular features that may be of interest and, as mentioned earlier under the discussion of Petrunkevitch's techniques, clear plastic wedges can be useful as props so that the orientation of the specimen can be changed. Particularly nice examples of amber spider photomicroscopy can be seen in Janzen (2002), Weitschat \& Wichard (2002), and Penney \& Green (2011).

Traditional light microscopy can be supplemented with confocal laser scanning microscopy (CLSM), which provides a non-destructive means of detecting morphological detail and three dimensional shape in amber inclusions, including those preserved in opaque amber. It is used to produce high resolution in-focus three dimensional images of thick sections by targeted fluorescence (Clark \& Daly, 2010) and can help to reveal more detail about characters that might otherwise remain ambiguous. Although it has not yet been used to image spiders, it has been applied to spider silk preserved in French amber (Saint Martin et al., 2014). Kirejtshuk et al. 
(2014) noted the importance of embedding medium with regard to the success of this technique. For example, specimens mounted in Canada Balsam can usually be studied with CLSM, but those mounted in epoxy resin cannot, because the autofluorescence of the latter medium totally masks that of the inclusion in the amber. Thomas et al. (2014) demonstrated the potential of confocal Raman microscopy as an informative and non-destructive method for identifying chemical information about an amber inclusion with minimal or no interference from the surface or surrounding matrix. For important reviews of microscopy of amber inclusions see Ascaso et al. (2003) and Speranza et al. (2010).

\subsection{Software}

The first software developed for digital photography is still the market leader: Adobe Photoshop. However, as its name implies, it is designed for post-shoot manipulation of images. Most camera manufacturers provide software for shooting and a lesser or greater degree of postprocessing. At the shooting stage, a typical set-up involves a DSLR and either manufacturer's or third-party software to set up the camera (e.g. to adjust ISO, colour temperature), to set the camera to live view, to view and adjust the image before capture, and to click the shutter (i.e. capture the image seen on the computer screen). The workflow described in Selden (2104) uses a Canon 5D (Mk I-IV) camera and DSLR Assistant software (dslrassistant.com); this software works with Canon DSLR cameras and Macintosh computers. In macrophotography, this (and similar) software can be programmed to take a series of images at slightly different focussing levels by moving the lens closer or further from the specimen in small, medium or large increments. This produces a series of shots which can then be stacked and merged to increase the depth of field. Images can be captured in any format, but it is preferable for the originals to be 
taken in RAW, because it holds the greatest amount of information, and then converted to another format (e.g. TIFF) for further manipulation. The RAW files should be stored as a backup. RAW conversion can be done in a variety of applications, including Photoshop.

The merging of image stacks (commonly called z-stacks because they align along a z-axis relative the $\mathrm{x}$ and $\mathrm{y}$ of the $2 \mathrm{D}$ photo plane) to achieve greater depth of field has revolutionized illustrations of fossils, especially those in amber. Because amber spiders are generally small but highly three-dimensional, it is almost impossible to get all parts in focus in a single shot. Therefore, the ability to stack photographs taken at different focussing levels enables beautiful, three-dimensional pictures to be produced (Figs. 9B-E). Matrix-preserved spiders, too, have some amount of relief, especially at higher magnifications, for which this method is invaluable (Fig. 9). The technique involves merging a series of photographs all taken of the same field of view, but at slightly different focussing levels, into a single, multi-layered file. The layers are first aligned, and then merged so that all of the out of focus parts of each layer are removed, leaving the in-focus areas. The resultant flattened file should give the impression of all parts of the image being in focus. Many software packages can do this, not only Photoshop but also a variety of specialist applications such as Helicon Focus, Zerene Stacker, and many others (https://en.wikipedia.org/wiki/Focus_stacking). A major problem with the process is the creation of artifacts, which can be particularly troublesome in photos of amber. It is advisable to keep the number of layers in a stack relatively small, and sometimes manual removal of poorly focussed areas helps to prevent them overriding the true, in-focus layer.

Another technique which is useful when a specimen might only be available for study for a short time, and the researcher needs to gather as much image as possible, is to take a mosaic of 
high-resolution images across the specimen (and each tile can be shot as stacks to be merged), then a panorama produced of the entire specimen. Each tile must have at least a $40 \%$ overlap with the next in order for the mosaic to work correctly. Photoshop has an automatic Photomerge function which can simplify the mosaic process, but it is usually more reliable to work tile by tile manually. A suggested workflow is given in Selden (2014). Again, there are specialist panorama packages, as well as other general photo manipulation software, which will do this. The result is a large file which shows the entire specimen, but which can be zoomed into much higher magnification, as if the specimen was being viewed under the microscope (Fig. 10A-B). This advantage of having the entire specimen at high resolution in one file is somewhat tempered by the file itself being rather large, so it is not easy to create a view without a large amount of computer memory available. Another technique which can sometimes be helpful is to superimpose the image of the part not that of the counterpart (flipped horizontally). An example of where this elucidated morphology is shown in Fig. 10C, where the spiral nature of the distal embolus of a plectreurid spider was revealed using this process (Selden \& Huang, 2010).

\section{Scanning Electron Microscopy}

The first attempt to use scanning electron microscopy (SEM) on a fossil spider was a preliminary report by Mierzejewski (1976a) on a study of a Baltic amber spider. To prepare his specimens, the amber was ground down as close as possible to the inclusion. Then, the remaining amber was plucked away to reveal the internal cavity of the fossilized spider; organs were removed with a badger hair (Mierzejewski, 1976b). The organic material was coated with goldpalladium and studied in a Jeol JSM-Sl using $10 \mathrm{kV}$ accelerating voltage. Mierzejewski's (1976a) figures show a book lung (fig. 1), haemolymph cells (fig. 2), an ampullate silk gland 
(fig. 3), and striated muscle (fig. 4). Early attempts to utilize SEM on rock matrix spiders did not reveal anything that could not be seen in light microscopy. For example, a tarsus of the uraraneid Attercopus fimbriunguis (Shear et al., 1987, figs. 138-139) showed similar features as seen using the compound microscope (Shear et al., 1987, figs. 136-137), and an attempt by Selden (2001) to see details of an Eocene spider using the (then) newly developed environmental SEM did not result in any morphology being revealed that was not seen in light microscopy.

Further developments in the technology of electron microscopy has led to the technique revealing features which are difficult or impossible to see in optical microscopy, as well as providing energy-dispersive X-ray (EDX) elemental mapping of the composition of some morphological features, as used by Selden et al. (2016, fig. 1, reproduced here in Fig. 11).

\section{CT and Synchrotron Scanning}

Virtual palaeontology, the study of three-dimensional reconstructions of fossils and their subsequent digital dissection using computers, is at the forefront of an ongoing revolution in palaeontology, and is becoming increasingly widely used by researchers worldwide (Sutton et al., 2014). These techniques not only produce highly detailed reconstructions of the external anatomy, but also provide important insights into the mode of preservation of amber inclusions, including the degree of preservation of internal organs (Fig. 13).

Over the last decade or so, high resolution X-ray computed tomography (HR-CT) has been applied to fossil amber (and copal) inclusions, including spiders, with startling results (Penney et al., 2007, 2011, 2012c,d; Bosselaers et al., 2010; McNeil et al., 2010; Dunlop et al., 2011, 2012). HR-CT images are calculated from a series of X-ray transmission images recorded at different angles and can produce micrometre-scale spatial resolution (Dierick et al., 2007); there is also 
potential for nanometre-scale resolution using nano-CT scanners (e.g. Moreau et al., 2014). HRCT provides a non-destructive, minimum preparation method for imaging minute morphological details, including internal morphology, and generates three-dimensional reconstructions that can be sectioned and viewed from multiple angles (Fig. 12). Essentially, it is possible to dissect an amber inclusion digitally (Fig. 13A-C). Examination of individual X-ray slices can help interpret finer details of the fossil morphology (e.g. Penney et al., 2011) (Fig. 12B). The technique can also be used to overcome the problem of the white emulsion coating (Verlumung) commonly encountered obscuring important taxonomic features of fossils in Baltic amber (Henderickx et al., 2006), for reconstructing internal preservation (Pohl et al., 2010), for the restudy of historical specimens in which the amber has darkened to the extent that the inclusion is difficult to view using traditional methods (Dunlop et al., 2011) (Fig. 14B), and for taphonomic investigations of resin topology (Coty et al., 2014).

Another way of achieving similar results is the application of propagation phase-contrast Xray synchrotron imaging, applied to fossil spiders in amber by Saupe et al. (2012) (Fig. 14C-D). This approach is particularly useful for microradiographic screening of bulk samples of completely opaque amber for inclusions. In addition, phase-contrast synchrotron imaging allows for increased contrast over absorption techniques, detecting inclusions that may not have been visible using more traditional $\mathrm{CT}$ methodologies.

Both the aforementioned scanning techniques use the same physical principles so the differences lie mainly in the fine details (temporal/lateral source coherence, propagation distance, fringe sampling, and so on), which are rather difficult to convey and explain succinctly in layman's terms. The main difference between laboratory-based and synchrotron-based phase 
contrast imaging lies in the intensity of the X-ray beam. An appropriate comparison might be between a pocket flashlight and a laser pointer: the former produces a dim cone of white light, the latter a single-coloured bright beam. Therefore, the synchrotron (Fig. 14C) can generally create a larger phase enhancement because the X-ray brightness is not compromised by pushing the detector farther back, and consists of a single colour (wavelength) of light. Nonetheless, incredible images can be obtained using HR-CT, but the scan times are much longer than those producing equivalent images using synchrotron imaging. Indeed, the high definition micro-CT scanning of fossil invertebrates has much improved over the past few years, whereby it is approaching the resolution of phase-contrast synchrotron microtomography (Henderickx \& Boone, 2014). The application of nano-CT can eventually be expected to yield very interesting results when applied to amber inclusions in the future. Whereas normal laboratory-based micro X-ray CT can achieve at best a resolution of approximately 500-600 nm, nano-CT can resolve down to $50 \mathrm{~nm}$.

The resulting data from these methods can be loaded into three-dimensional printers in order to make a large physical model of the inclusion (e.g. Penney, 2013) (Fig. 14E). This creates the opportunity for virtual libraries of CT data or even $3 \mathrm{D}$ reconstructions that can be electronically dissected on, or printed in 3D from, any computer anywhere in the world. An online data archive that allows researchers to store, organize, share and distribute their own 3D data is already available (www.morphosource.org), but does not include any amber inclusions as yet. In the future, scientists can expect a reduced need for physical loans of unique (e.g. holotype) specimens from museums. They will need only to log on to these databases via a laptop, of possibly even a mobile phone! 
The scan data can also be used to make video clips, which are now increasingly used as online supporting materials to published papers and some have also been made freely available on the internet. These videos are a great way for engaging the public in our science. For example, the video clip of a CT study of a hunstsman spider (Araneae: Sparassidae) in Baltic amber by Dunlop et al. (2011) (Fig. 14B) had received 188,239 views (at 9 May, 2015), which roughly equates to 126 views per day for each of the 1495 days that it has been online since being uploaded on 6 April 2011. By comparison, the paper had been cited only 18 times in academic journals!

Some museum curators are reluctant to loan specimens for research using these techniques because of concerns relating to the long-term physico-chemical effects of X-ray exposure. However, the current consensus is that the amber matrix does not appear to suffer any serious consequences as a result of exposure to standard CT scans, based on a study by Bertini et al. $(2014,2016)$, who noted only subtle depolymerization and oxidation chemical changes in some of their samples similar to a photo-ageing mechanism, although synchrotron scanning generated a visible discoloration in both amber and copal samples. Van de Kamp et al. (2014) noted that intense synchrotron-based X-rays, and in particular the polychromatic radiation employed for high-throughput experiments, usually resulted in browning of the amber, but that this browning was not persistent and faded after a couple of months.

It should be noted that these techniques are expensive and have not progressed to the point where they are a total replacement for traditional methods. Not all specimens are resolved to the same degree and this probably relates to differences in contrast between the inclusion and the surrounding amber matrix, in addition to the software used to reconstruct the images. For 
example, Dunlop \& Mrugalla (2015) were unable to generate any useful data when they attempted to CT scan an amblypygid (?exuvium) in Miocene Mexican amber. Although Andersen et al. (2015) were able to observe good contrast between their specimen of a chironomid pupa and the surrounding Baltic amber, they did not achieve the resolution necessary to resolve fine details. Sometimes different parts of the same specimen will exhibit differential reconstruction potential. For example, in the Baltic amber anapid spider described by Penney et al. (2011) one pedipalp was reconstructed reasonably well whereas the other was not, despite both appearing similar under the light microscope (Fig. 12).

McNeil et al. (2010) scanned various amber spiders and described three different strategies for dealing with the phase artifacts inherent to reconstructing CT scans (Fig. 14A), in order to give a clean segmentation of important features required for the classification of new species. These included: 1. Phase retrieval and automatic segmentation, with artifacts reduced by preprocessing the projections using the TIE phase retrieval algorithm; 2. Manual segmentation from direct reconstruction, which allows artifacts to be avoided by taking advantage of sharp, high contrast edge fringes, but this approach is labour intensive because each reconstructed slice needs to be examined and segmented by hand; 3. Semi-automatic segmentation from bright and dark fringes, which proved useful where phase retrieval using the TIE algorithm was problematic due to absorption gradients.

The issue of differential reconstruction potential of amber fossils was further examined by Van de Kamp et al. (2014), who found a considerable degree of variation, but were unable to correlate this with any physico-chemical characteristics of the fossil resins. They concluded that it was impossible to predict the degree of preservation of an inclusion by its shape or appearance. 
Many turned out to be merely arthropod-shaped voids. Other inclusions contained undefined particles and some showed an astonishingly well-preserved anatomy suitable for taxonomic studies based on internal characters. These authors also noted that preservation varied between anatomical structures. While the musculature of one specimen was well preserved, reflecting its original condition, other organs and the exoskeleton were completely degenerated. In rare cases, specimens that looked fine under a stereomicroscope, were not visible at all using X-rays.

Additional problems were discussed by Riedel et al. (2012). When the external cuticle of the amber inclusions is degraded and covered by a fine network of cracks (as is rather common), the presence of such artificial sutures creates problems in the reconstruction because they interfere with natural structures of the specimen. It is possible to rectify such artifacts by manual segmentation, but the risk of introducing inaccuracies is substantial, even if care is taken and much time is invested. In addition, inclusions of debris present another challenge. If they are separated from the specimen, they can be removed easily during post-processing, but debris or bubbles in direct contact with the specimen are more difficult and time consuming to remove. Synthetic resins used to embed amber pieces often have a different absorption potential and may suffer heat damage during the scan (Riedel et al., 2012).

\section{Discussion}

Early depictions of fossil spiders were hampered by the technology available, in comparison to the fine morphological details that can be visualized today. As optical systems developed, so more and more features became visible to researchers, in both living and fossil spiders. By 1878, Bertkau was able to show drawings of male pedipalps and tarsal claws, but it was 35 years later that the first photographs of fossil spiders were published (Petrunkevitch, 1913). At first, 
photographs were not especially helpful, and this remains the case if the photographs are poorly made and printed, and explanatory drawings are too sketchy to be helpful either. Part of the problem, especially with amber, is the lack of depth of field, as explained above. Digital photography and z-stacking have got around this problem, and today, CT scanning can even reveal hidden morphology.

Of especial importance, is whether diagnostic characters can be seen in fossil spiders. As previously mentioned, the characters used by neontologists to classify spiders can be small and hidden. Nevertheless, even in rock-matrix preserved spiders, diagnostic features such as presence of a calamistrum (Fig. 15F), tarsal claws (Fig. 11A), structure and arrangement of trichobothria (Fig. 15C-E), and ultrastructure of setae (Fig. 11B-E) can be seen under a good stereomicroscope or with SEM; even internal structure can be made out with light microscopy (Fig. 15A-B) and CT scanning (Fig. 13A). In this respect, some exceptionally preserved fossil spiders can be considered to be taxonomically subequal to living spiders, and can be used in cladistic analyses (Harms \& Dunlop, 2009; Wood et al., 2013).

\section{The Future}

Hitherto, only amber spiders had been subjected to CT scanning but, recently, a palpimanid spider from the Cretaceous Crato Formation of Brazil, nicely preserved in three dimensions (Fig. 1), was subjected to synchrotron CT scanning. Fig. 16A is a section through the specimen showing details of internal structure, and Fig. 16B-C show three-dimensional reconstructions of dorsal and ventral sides of the specimen, respectively. The recent CT revolution has demonstrated the importance and impact of this approach to the study of 3D fossils, especially those preserved in amber, although the method has yet to be applied more widely on matrix- 
preserved fossils. However, it is still in its early stages and is a rapidly developing field. Future advances in palaeontological applications are unlikely to be limited to refinements of established techniques (Sutton et al., 2014).

New techniques are being tested all the time. For example, Reflectance Transformation Imaging (RTI) is making great headway in the study of matrix-preserved insect fossils, in which low-angle light from many directions can be manipulated to reveal minor details of wing venation (Béthoux et al., 2016). This could be of use in certain specimens of fossil spiders. Elemental analysis, used to identify organic material in Selden et al. (2016), could be extended to search for particular compounds in fossil spiders: pigmentation for example. Evidence for original colouration (rather than simply patterning), both structural and chemical, have been found in fossils (e.g. Colleary et al., 2012; Glass et al., 2012; Vitek et al., 2013; Vinther, 2015; Edwards et al., 2016). So, pigmentation and/or structural colours could be discovered in fossil spiders using these techniques.

Despite the remarkable preservation of fossils in amber, some neontologists still tend to omit them in their studies, some claiming that they are far too taxonomically inferior to living forms. However, new visualization methodologies demonstrate a potentially high degree of phylogenetic inference from even very tiny amber inclusions and new imaging technology is certainly narrowing the gap between neontological and palaeontological taxonomy.

\section{Acknowledgments}

PAS thanks Xavier Delcòs, Vincent Perrichot, Erin Saupe, Carmen Soriano, Paul Tafforeau, for synchrotron CT scanning; Claire Mellish and staff of the NHM for help with photography; The Leverhulme Trust, Natural Environment Research Council, the Alexander von Humboldt 
Foundation, and the University of Kanas for funding; and for Fig. 16, Carmen Soriano and the resources of the Advanced Photon Source, a US Department of Energy (DOE) Office of Science User Facility operated for the DOE Office of Science by Argonne National Laboratory under Contract No. DE-AC02-06CH11357. DP thanks David I. Green for help with amber photomicroscopy over the years, and Andrew McNeil for assistance with his computed tomography studies.

\section{References}

Andersen, T., Baranov, V., Goral, T., Langton, P., Perkovsky, E. \& Sykes, D. 2015. First record of a Chironomidae pupa in amber. Geobios, http://dx.doi.org/10.1016/j.geobios. 2015.06.004.

Ascaso, C., Wierzchos, J., Corral, C., López del Valle, R. \& Alonso, J. 2003. New applications of light and electron microscopic techniques for the study of microbiological inclusions in amber. Journal of Paleontology, 77: 1182-1192.

Azar, D. 1997. A new method for extracting plant and insect fossils from Lebanese amber. Palaeontology, 40: 1027-1029.

Baird, G.C., Sroka, S.D., Shabica, C.W. \& Kuecher, G.J. 1986. Taphonomy of Middle Pennsylvanian Mazon Creek area fossil localities, northeast Illinois: significance of exceptional fossil preservation in syngenetic concretions. Palaios 1, 271-285.

Baranov, V., Andersen, T. \& Perkovsky, E. 2014. Orthoclads from Eocene amber from Sakhalin (Diptera: Chironomidae: Orthocladiinae). Insect Systematics \& Evolution, 45: 1-20. 
Barling, N., Martill, D.M., Heads, S.W. \& Gallien, F. 2015. High fidelity preservation of fossil insects from the Crato Formation (Lower Cretaceous) of Brazil. Cretaceous Research, 52, $605-622$.

Bertini, M., Ball, A.D., Mellish, C., Burgio, L., Shah, B., Pretzel, B., Blagoderov, V., Goral, T., Sykes, D., Summerfield, R., Steart, D., Garwood, R.J., Spencer, A.R.T., Ross, A. \& Penney, D. 2014. A risk assessment to determine whether amber is altered by microCT or confocal microscopy studies: using optical microscopy, FTIR and Raman spectroscopy. Abstracts of the annual conference of the Society for the Preservation of Natural History Collections, Cardiff, 2014.

Bertini, M., Ball, A.D., Mellish, C., Shah, B., Pretzel, B., Burgio, L., Goral, T., Sykes, D., Summerfield, R., Steart, D., Blagoderov, V., Garwood, R.J., Spencer, A.R.T., Penney, D. \& Ross, A. 2016. Is amber altered by microCT or confocal microscopy studies? A preliminary assessment using optical microscopy, FTIR and Raman spectroscopy. In: Penney, D. \& Ross A.J. (eds) 7th international conference on fossil insects, arthropods and amber: 67 (poster abstract).

Bertkau, P. 1878a. Einige Spinnen und ein Myriapode aus der Braunkohle von Rott. Verhandlungen des Naturhistorischen Vereins der Preussischen Rheinlande und Westfalens, Bonn 35, 346-360, pl. 5.

Béthoux, O., Llamosi, A. \& Toussaint, S. 2016. Reinvestigation of Protelytron permianum (Insecta; Early Permian; USA) as an example for applying reflectance transformation imaging to insect imprint fossils. Fossil Record, 20: 1--7. 
Bloch, M.E. 1776. Beytrag zur Naturgeschichte des Kopals. Beschäftigungen der Berlinischen Gesellschaft Naturforschender, 2, 91-196.

Bosselaers, J., Dierick, M., Cnudde, V., Masschaele, B., Van Hoorebeke, L. \& Jacobs, P. 2010. High-resolution X-ray computed tomography of an extant new Donuea (Araneae: Liocranidae) species in Madagascan copal. Zootaxa, 2427: 25-35.

Bottali, P. 1975. Note su due rari esemplari di Araneidi (Aracnidi) rinvenuti nei depositi diatomitici (Facies lacustre) di Riano Flaminio (Roma). Fragmenta Entomologica 11: $169-174$.

Breynio, J.P. 1726. Observatio de succinea gleba, plantae cujusdam folio impraegnata, rarissima. Philosophical Transactions of the Royal Society of London 34, 154-156. Fig. 2.

Briggs, D.E.G., Stankiewicz, B.A., Meischner, D., Bierstedt, A. and Evershed, R.P. 1998. Taphonomy of Arthropod Cuticles from Pliocene Lake Sediments, Willershausen, Germany. PALAIOS, 13, 386-394.

Buckland, W. 1837. The Bridgewater treatises on the power wisdom and goodness of God as manifested in the creation. Geology and mineralogy considered with reference to natural theology. Volume 2. 2nd edition. William Pickering, London. 129 pp.

Clark, N.D.L. \& Daly, C.J. 2010. Using confocal laser scanning microscopy to image trichome inclusions in amber. Journal of Paleontological Techniques, 8: 1-7.

Clerck, C. 1757. Svenska spindlar, uti sina hufvud-slågter indelte samt under några och sextio särskildte arter beskrefne och med illuminerade figurer uplyste. L. Salvii, Stockholm. 154 pp. 
Cloudsley-Thompson, J.L. 2001. Scorpions and spiders in mythology and folklore. In Scorpions 2001. In Memoriam Gary A. Polis (eds. V. Fet \& P.A. Selden), pp. 391-402. British Arachnological Society, Burnham Beeches, Bucks.

Cody, G.D., Gupta, N.S., Briggs, D.E.G., Kilcoyne, A.L.D., Summons, R.E., Kenig, F., Plotnick, R.E. \& Scott, A.C. 2011. Molecular signature of chitin-protein complex in Paleozoic arthropods. Geology, 39, 255-258.

Colleary, C., Dolocan, A., Gardner, J., et al. 2015. Chemical, experimental, and morphological evidence for diagenetically altered melanin in exceptionally preserved fossils. Proceedings of the United States National Museum, 112, 12592-12597.

Conway Morris, S., Selden, P.A., Gunther, G., Jamison, P.G. \& Robison, R.A. 2015. New records of Burgess Shale-type taxa from the middle Cambrian of Utah. Journal of Paleontology, $1-13$.

Coty, D., Aria, C., Garrouste, R., Wils, P., Legendre, F. \& Nel, A. 2014. The first ant-termite syninclusion in amber with CT-scan analysis of taphonomy. PLoS ONE, 9(8): e104410.

Crighton, W.R.B. \& Carrió, V. 2007. Photography of amber inclusions in the collections of National Museums Scotland. Scottish J. Geol., 43: 89-96.

Cutler, B. 1970. A fossil crab spider from west-central Wyoming (Araneae: Thomisidae). Entomological News, 81, 38-40.

Dalla Vecchia, F. \& Selden, P.A. 2013. A Triassic spider from Italy. Acta Palaeontologica Polonica, 58: 325-330. 
Dierick, M., Cnudde, V., Masschaele, B., Vlassenbroeck, J., Van Hoorebeke, L. \& Jacobs, P. 2007. Micro-CT of fossils preserved in amber. Nuclear Instruments and Methods in Physics Research A 580: 641-643.

Dunlop, J.A. \& Jekel, D. 2008. The oldest available fossil arachnid name. Palaeodiversity, 1, 8792.

Dunlop, J.A. \& Mrugalla, B. 2015. Redescription of the Chiapas amber whip spider Electrophrynus mirus (Amblypygi). Journal of Arachnology, 43: 220-223.

Dunlop, J.A. \& Penney, D. 2009. Case 3475 Myrmarachne MacLeay, 1839 (Araneae, SALTICIDAE): proposed conservation of the generic name. Bulletin of Zoological Nomenclature, 66, 1.

Dunlop, J.A., Penney, D., Daluge, N., Jäger, P., McNeil, A., Bradley, R., Whithers, P.J. \& Preziosi, R.F. 2011. Computed tomography recovers data from historical amber: an example from huntsman spiders. Naturwissenschaften, 98: 519-527.

Dunlop, J.A., Menon, F. \& Selden, P.A. 2007. Arachnida: spiders, scorpions and allies. In The Crato fossil beds of Brazil. Window into an ancient world (eds. D. M. Martill, G. Bechly \& R. F. Loveridge). pp. 103-132. Cambridge University Press, Cambridge.

Dunlop, J.A., Penney, D. \& Jekel, D. 2016. A summary list of fossil spiders. In World spider catalog, version 17.5. Bern: Natural History Museum, online at http://wsc.nmbe.ch Dunlop, J.A., Wirth, S., Penney, D., McNeil, A., Bradley, R.S.,Withers, P.J. \& Preziosi, R.F. 2012. A minute fossil phoretic mite recovered by X-ray computed tomography. Biology Letters, 8: 457-460. 
Edwards, N.P., van Veelen, A., Anné, J., Manning, P.L., Bergmann, U., Sellers, W.I., Egerton, V.M., Sokaras, D., Alonso-Mori, R., Wakamatsu, K., Ito, S. \& Wogelius, R. A. 2016. Elemental characterisation of melanin in feathers via synchrotron X-ray imaging and absorption spectroscopy. Scientific Reports, 6:34002: 1-10.

Eskov, K.Y. 1984. A new fossil spider family from the Jurassic of Transbaikalia from (Araneae: Chelicerata). Neues Jahrbuch für Geologie und Paläontologie, Monatshefte 1984, 645653.

Eskov, K.Y. 1987. A new archaeid spider (Chelicerata: Araneae) from the Jurassic of Kazakhstan, with notes on the so-called "Gondwanan" ranges of recent taxa. Neues Jahrbuch für Geologie und Paläontologie, Abhandlungen 175, 81-106.

Eskov, K.Y. \& Selden, P.A. 2005. First record of spiders from the Permian period (Araneae: Mesothelae). Bulletin of the British Arachnological Society 13, 111-116.

Eskov, K.Y. \& Zonstein, S. 1990. First Mesozoic mygalomorph spiders from the Lower Cretaceous of Siberia and Mongolia, with notes on the system and evolution of the infraorder Mygalomorphae (Chelicerata: Araneae). Neues Jahrbuch für Geologie und Paläontologie, Abhandlungen 178, 325-368.

Feldmann, R.M., Vega, F.J., Applegate, S.P. \& Bishop, G.A. 1998. Early Cretaceous arthropods from the Tlayúa Formation at Tepexi de Rodríguez, Puebla, México. Journal of Paleontology 72, 79-90.

Garwood, R.J., Dunlop, J.A., Selden, P.A., Spencer, A.R.T., Atwood, R.C., Vo, N.T. \& Drakopoulos, M. 2016. Almost a spider: a 305-million-year-old fossil arachnid and spider origins. Proc. Biol. Sci., 283, 20160125-8. 
Gertsch, W.J. 1949. American spiders. Van Nostrand, New York. xiii +285 pp.

Glass, K., Ito, S., Wilby, P.R., et al. 2012. Direct chemical evidence for eumelanin pigment from the Jurassic period. PNAS, 109, 10218-10223.

Grimaldi, D.A., Shedrinsky, A., Ross, A.J. \& Baer, N.S. 1994. Forgeries of fossils in 'amber': history, identification and case studies. Curator, 37: 251-274.

Gupta, N.S., Kilcoyne, A. \& Briggs, D. 2010. Identification of chitin preserved in a Pennsylvanian age fossil scorpion cuticle. Astrobiology Science Conference 2010.

Hand, S., Archer, M., Bickel, D., Creaser, P., Dettmann, M., Godthelp, H., Jones, A., Norris, B. \& Wicks, D. 2010. Australian amber. Pp. 69-79 in: Penney, D. (ed.) 2010. Biodiversity of fossils in amber from the major world deposits. Siri Scientific Press, Manchester.

Harger, O. 1874. Notice of a new spider from the Coal Measures of Illinois. American Journal of Science 7, 219-223.

Harms, D. \& Dunlop, J.A. 2009. A revision of the fossil pirate spiders (Arachnida: Araneae: Mimetidae). Palaeontology, 52: 779-802.

Haug, J.T., Haug, C., Maas, A., Fayers, S.R., Trewin, N.H. \& Waloszek, D. 2009. Simple 3D images from fossil and Recent micromaterial using light microscopy. Journal of Microscopy, 233: 93-101.

Heer, O. 1865. Die Urwelt der Schweiz. Friedrich Schultheß, Zurich, xxix +622 pp., 11 pls., 1 map.

Heer, O. 1872. Le monde primitif de la Suisse. H. Georg, Genève and Basle, 801 pp. [French translation of Heer 1865]. 
Heer, O. 1876. The primaeval world of Switzerland. Volume 2. Heywood, J. (ed.). Longmans, Green and Co., London, 324 pp. [English translation of Heer 1865].

Henderickx, H. \& Boone, M. 2014. The first fossil Feaella Ellingsen, 1906, representing an unexpected pseudoscorpion family in Baltic amber (Pseudoscorpiones: Feaellidae). Entomo-Info, 25: 5-11.

Henderickx, H., Cnudde, V., Masschaele, B., Dierick, M., Vlassenbroeck, J. \& Van Hoorebeke, L. 2006. Description of a new fossil Pseudogarypus (Pseudoscorpiones:

Pseudogarypidae) with the use of X-ray micro-CT to penetrate opaque amber. Zootaxa, 1305: 41-50.

Henwood, A. 1993. Recent plant resins and the taphonomy of organisms in amber: a review. Mod. Geol., 19: 35-59.

Heyden, C. von 1859. Fossile Insekten aus der Rheinischen Braunkohle. Palaeontographica 8, 115 ; pl. 1 .

Hillyard, P. 1994. The book of the spider: from arachnophobia to the love of spiders. Hutchinson: London. 196 pp.

Holl, F. 1829. Handbuch der Petrefactenkunde. Hilscher, Dresden. 489 pp.

Hong, Y-C. 1985. Fossil insects, scorpionids and araneids in the diatoms of Shanwang. Geological Publishing House, Beijing. 80 pp., 33 pls. [In Chinese, English summary]

Hopkins, D.M., Giterman, R.E. \& Matthews, J.V. 1976. Interstadial mammoth remains and associated pollen and insect fossils, Kotzebue Sound area, northwestern Alaska. Geology, 4, 169-172. 
ICZN. 2010. Opinion 2258 (Case 3475) Myrmarachne MacLeay, 1839 (Araneae, conserved Salticidae): generic name. Bulletin of Zoological Nomenclature 67(4).

Janzen, J.-W. 2002. Arthropods in Baltic amber. Ampyx-Verlag Dr Andreas Stark, Halle, 167 pp.

Jell, P.A. \& Duncan, P.M. 1986. Invertebrates, mainly insects, from the freshwater, Lower Cretaceous, Koonwarra Fossil Bed (Korumburra Group), South Gippsland, Victoria. Memoirs of the Association of Australasian Palaeontologists 3, 111-205.

Kaulfuss, U., Lee, D.E., Bannister, J.M., Lindqvist, J.K., Conran, J.G., Mildenhall, D.C., Kennedy, E.M., Perrichot, V., Maraun, M. \& Schmidt, A. 2013. Foulden Maar and South Island amber (New Zealand) - two exceptional windows into Southern Hemisphere Cenozoic terrestrial ecosystems. In: Reitner et al. (eds) Palaeobiology and geobiology of fossil Lagerstätten through Earth history: 84-89 (talk abstract).

Kaulfuss, U., Lee, D.E., Barratt, B.I.P., Leschen, R.A.B., Larivière, M.-C., Dlussky, G.M., Henderson, I.M. \& Harris, A.C. 2014. A diverse fossil terrestrial arthropod fauna from New Zealand: evidence from the early Miocene Foulden Maar fossil lagerstätte. Lethaia, 48, 299-308.

Kaulfuss, U., Lee, D. \& Schmidt, A. 2016. New discoveries of Miocene arthropods from amber and diatomite deposits in New Zealand. In: Penney, D. \& Ross A.J. (eds) 7th international conference on fossil insects, arthropods and amber: 26 (talk abstract).

Kirejtshuk, A.G., Chetverikov, P.E. \& Azar, D. 2014 (online, published in print 2015). Libanopsinae, new subfamily of the family Sphindidae (Coleoptera: Cucujoidea) from Lower Cretaceous Lebanese amber, with remarks on using confocal microscopy for the study of amber inclusions. Cretaceous Research, 52: 461-479. 
Koch, C.L. \& Berendt, G.C. 1854. Die im Bernstein befindlichen Crustaceen, Myriapoden, Arachniden und Apteren der Vorwelt. In: Berendt, G.C. (ed) Die im Bernstein befindlichen organischen Reste der Vorwelt. Vol. 1, part II. Nicholaischen Buchhandlung, Berlin.

Kundmann, J.C. 1737. Rariora naturae et artis, item in re medica, oder Seltenheiten der Natur und Kunst des Kundmannischen Naturalien Cabinets, wie auch in der ArtzeneyWissenschaft. M. Hubert, Breslau \& Leipzig.

Leech, R. \& Matthews, J.V. 1971. Xysticus archaeopalpus (Arachnida: Thomisidae), a new species of crab spider from Pliocene sediments in western Alaska. Canadian Entomologist 103, 1337-1340.

Leroy, A. \& Leroy, J. 2003. Spiders of southern Africa. 2nd edition. Struik, Cape Town. 96 pp. Licht, E.L. 1986. Araneid taphonomy: a paleo thermometer. In Proceedings of the Ninth International Congress of Arachnology, Panama 1983 (eds. W. G. Eberhard, Y. D. Lubin \& B. C. Robinson), pp. 163-165. Smithsonian Institution Press, Washington DC.

Linnaeus, C. 1758. Systema naturae per regna tria naturae, secundum classes, ordines, genera, species cum characteribus differentiis, synonymis, locis. 10th edition. Holm. 821 pp.

Lhwyd, E. 1699. Lithophylacii Britannici Ichnographia. London. 139 pp., pls I-XXIII.

MacLeay, W.S. 1839. On some new forms of Arachnida. Annals of Natural History 2: 1-14

Martill, D.M. ed.. (1993). Fossils of the Santana and Crato Formations, Brazil. Field Guides to Fossils 5. The Palaeontological Association, London, 159 pp.

Martínez-Delclòs, X., Briggs, D.E.G. \& Peñalver, E. 2004. Taphonomy of insects in carbonates and amber. Palaeogeography, Palaeoclimatology, Palaeoecology, 203: 19-64. 
Mazur, N., Nagel, M., Leppin, U., Bierbaum, G. \& Rust, J. 2014. The extraction of fossil arthropods from Lower Eocene Cambay amber. Acta Palaeontologica Polonica, 59: 455-459.

McNeil, A., Bradley, R.S., Withers, P.J. \& Penney, D. 2010. Imaging fossilised spiders in amber using lab-based phase contrast X-ray tomography. In: Stock, S.R (ed.) Developments in X-ray tomography VII. Proc. SPIE, San Diego, 7804: 78041Q1-7.

Menge, A. 1854. Footnotes in Koch, C.L. \& Berendt, G.C. 1854. Die im Bernstein befindlichen Crustaceen, Myriapoden, Arachniden und Apteren der Vorwelt. In Die im Bernstein befindlichen organischen Reste der Vorwelt. Vol. 1, part II (ed. G.C. Berendt). Nicholaischen Buchhandlung, Berlin. i-iv + 1-124 pp., 17 pls.

Menge, A. 1856. Lebenszeichen vorweltlicher, im Bernstein eingeschlossener Thiere. Programm der öffentlichen Prüfung der Schüler der Petrischule, Danzig. 32 pp.

Mesquita, M.V. 1996. Cretaraneus martinsnetoi n. sp. (Araneoidea) da Formação Santana, Cretáceo Inferior da Bacia do Araripe. Revista Universidade Guarulhos, Geociências 6, $24-31$.

Mierzejewski, P. 1976a. Scanning electron microscope studies on the fossilization of Baltic amber spiders (preliminary note). Ann. Med. Sec. Pol. Acad. Sci., 21: 81-82.

Mierzejewski, P. 1976b. On application of scanning electron microscope to the study of organic inclusions from the Baltic amber. Rocznik Polskiego Towarzystwa Geologicznego, 46, 291-295.

Moreau, J.-D., Cloetens, P., Gomez, B., Daviero-Gomez, V., Néraudeau, D., Lafford, T.A. \& Tafforeau, P. 2014. Multiscale 3D virtual dissections of 100-million-year-old flowers 
using X-ray synchrotron micro- and nanotomography. Microscopy and Microanalysis, 20: $305-312$.

Nohra, Y., Azar, D., Gèze, R., Maksoud, S., El-Samrani, A. \& Perrichot, V. 2013. New Jurassic amber outcrops from Lebanon. Terrestrial Arthropod Reviews, 6: 27-51.

Palmer, A.R. 1957. Miocene arthropods from the Mojave Desert California. Geological Survey Professional Paper 294-G, 237-280, pls 30-34.

Penney, D. 2002. Paleoecology of Dominican amber preservation-spider (Araneae) inclusions demonstrate a bias for active, trunk-dwelling faunas. Paleobiology, 28: 389-398.

Penney, D. 2005. Fossil blood droplets in Miocene Dominican amber yield clues to speed and direction of resin secretion. Palaeontology, 48: 925-927.

Penney, D. 2007. A new fossil oonopid spider, in lowermost Eocene amber from the Paris Basin, with comments on the fossil spider assemblage. African Invertebrates, 48: 71-75.

Penney, D. 2008. Dominican amber spiders: A comparative palaeontological-neontological approach to identification, faunistics, ecology and biogeography. Siri Scientific Press, Manchester.

Penney, D. (ed.) 2010a. Biodiversity of fossils in amber from the major world deposits. Siri Scientific Press, Manchester.

Penney, D. 2010b. The evolution of jumping spiders (Araneae: Salticidae): the palaeontological evidence. Peckhamia, 81.8, 1-3.

Penney, D. 2013. Palaeontology: interpretation and application of the spider fossil record. Pp. 282-313 in: Penney, D. (ed.) Spider research in the 21 st century: trends and perspectives. Siri Scientific Press, Manchester. 
Penney, D. 2016. Amber Palaeobiology: Research trends and perspectives for the 21st century, 128 pp. Siri Scientific Press, Manchester.

Penney, D. \& Green, D. 2011. Fossils in amber: Remarkable snapshots of prehistoric forest life. Siri Scientific Press, Manchester.

Penney, D. \& Selden, P.A. 2011. Fossil spiders: the evolutionary history of a mega-diverse order. Monograph Series, Volume 1. Siri Scientific Press, Manchester.

Penney, D., Dierick, M., Cnudde, V., Masschaele, B., Vlasssenbroeck, J., Van Hoorebeke, L. \& Jacobs, P. 2007. First fossil Micropholcommatidae (Araneae), imaged in Eocene Paris amber using X-ray computed tomography. Zootaxa, 1623: 47-53.

Penney, D., Green, D.I., McNeil, A., Bradley, R., Marusik, Y.M., Withers, P.J. \& Preziosi, R.F. 2011. A new species of anapid spider (Arthropoda: Araneae: Anapidae) in Eocene Baltic amber, imaged using X-ray computed tomography. Zootaxa, 2742: 61-68.

Penney, D., Dunlop, J.A. \& Marusik, Y.M. 2012a. Summary statistics for fossil spider species taxonomy. ZooKeys, 192: 1-13.

Penney, D., Green, D.I., Titchener, S.B, Titchener, B.G., Brown, T.A. \& Preziosi, R.F. 2012b. An unusual palaeobiocoenosis of (sub)fossil spiders in Colombian copal. Bulletin of the British Arachnological Society, 15: 241-244.

Penney, D., McNeil, A., Green, D.I., Bradley, R., Whithers, P.J. \& Preziosi, R.F. 2012c. The oldest fossil pirate spider (Araneae: Mimetidae), in Uppermost Eocene Indian amber, imaged using X-ray computed tomography. Bulletin of the British Arachnological Society, 15: 299-302. 
Penney, D., Green, D.I., McNeil, A., Bradley, R., Marusik, Y., Whithers, P.J. \& Preziosi, R.F. 2012d. A new species of Craspedisia (Araneae: Theridiidae) in Miocene Dominican amber, imaged using X-ray computed tomography. Paleontological Journal, 46: 583-588.

Penney, D., Wadsworth, C., Green, D.I., Kennedy, S.L., Preziosi, R.F. \& Brown, T.A. 2013. Extraction of inclusions from (sub)fossil resins with description of a new species of stingless bee (Apidae: Meliponini) in Colombian copal. Paleontological Contributions, 7: $1-6$.

Penney, D., Wheater, C.P. \& Selden, P.A. 2003. Resistance of spiders to Cretaceous-Tertiary extinction events. Evolution 57, 2599-2607.

Perrichot, V. \& Néraudeau, D. 2014. Introduction to thematic volume "Fossil arthropods in Late Cretaceous Vendean amber (northwestern France). Paleontological Contributions, 10A: $1-4$.

Perrichot, V., Boudinot, B.E., Cole, J., Delhaye-Prat, V., Esnault, J., Goldman, Y., Nohra, Y.A. \& Schmidt, A.R. 2016. African fossiliferous amber: a review. In: Penney, D. \& Ross A.J. (eds) 7th international conference on fossil insects, arthropods and amber: 41 (talk abstract).

Petrunkevitch, A.I. 1913. A monograph of the terrestrial Palaeozoic Arachnida of North America. Transactions of the Connecticut Academy of Arts and Sciences 18, 1-137.

Petrunkevitch, A.I. 1942. A study of amber spiders. Transactions of the Connecticut Academy of Arts and Sciences 34, 119-464. Pls I-LXIX.

Petrunkevitch, A.I. 1946. Fossil spiders in the collection of the American Museum of Natural History. American Museum Novitates 1328, 1-36. 
Petrunkevitch, A.I. 1949. A study of Palaeozoic Arachnida. Transactions of the Connecticut Academy of Arts and Sciences 37, 69-315.

Petrunkevitch, A.I. 1950. Baltic amber spiders in the Museum of Comparative Zoology. Bulletin of the Museum of Comparative Zoology at Harvard College 103, 259-337.

Petrunkevitch, A.I. 1953. Paleozoic and Mesozoic Arachnida of Europe. Geological Society of America Memoir 53, 1-128.

Petrunkevitch, A.I. 1958. Amber spiders in European collections. Transactions of the Connecticut Academy of Arts and Sciences 41, 97-400.

Pocock, R.I. 1892. Liphistius and its bearing upon the classification of spiders. Annals and Magazine of Natural History, Series 6 10, 306-3 14.

Pohl, H., Wipfler, B., Grimaldi, D.A, Beckmann, F. \& Beutel, R.G. 2010. Reconstructing the anatomy of the 42 million-year-old fossil $\uparrow$ Mengea tertiara (Insecta: Strepsiptera). Naturwissenschaften, 97: 855-859.

Riedel, A., dos Santos Rolo, T., Cecilia, A. \& van de Kamp, T. 2012. Sayrevilleinae Legalov, a newly recognised subfamily of fossil weevils (Coleoptera: Curculionoidea: Attelabidae) and the use of synchrotron microtomography to examine inclusions in amber. Zoological Journal of the Linnean Society, 165: 773-794.

Roemer, F. 1866. Protolycosa anthracophila, eine fossile Spinne aus dem Steinkohlengebirge Oberschlesiens. Neues Jahrbuch für Mineralogie, Geologie und Paläontologie 1866, 136143, pl. 3 .

Rust, J., Singh, H., Rana, R.S., McCann, T., Singh, L., Anderson, K., Sarkar, N., Nascimbene, P.C., Stebner, F., Thomas, J.C., Solórzano Kraemer, M., Williams, J.C., Engel, M.S., 
Sahni, A. \& Grimaldi, D.A. 2010. Biogeographic and evolutionary implications of a diverse paleobiota in amber from the early Eocene of India. Proceedings of the National Academy of Sciences USA, 107: 18360-18365.

Saint Martin, J.-P., Saint Martin, S., Bolte, S. \& Néraudeau, D. 2014. Spider web in Late Cretaceous French amber (Vendée): the contribution of 3D image microscopy. Comptes Rendus Palevol, 13: 463-472.

Saupe, E.E., Pérez de la Fuente, R., Selden, P.A., Delclòs, X., Tafforeau, P. \& Soriano, C. 2012. New Orchestina Simon, 1882 (Araneae: Oonopidae) from Cretaceous ambers of Spain and France: first spiders imaged using phase-contrast X-ray synchrotron microtomography. Palaeontology, 5: 127-143.

Schawaller, W. 1982. Zur fossilen Spinnenfauna des Pliozäns von Willershausen in Norddeutschland (Arachnida, Araneae). Bericht der naturhistorischen Gesellschaft zu Hannover 125, 89-95.

Schawaller, W. \& Ono, H. 1979. Fossile Spinnen aus miozänen Sedimenten des Randecker Maars in SW-Deutschland (Arachnida: Araneae). Jahreshefte der Gesellschaft für Naturkunde in Württemberg 134, 131-141.

Schiodte, J.C. 1849. Om en afvigende Slaegt af Spindlerrnes Orden. Naturhistoriske Tidsskrift 2, 617-624. Pl. IV.

Schmidt, A.R., Perrichot, V., Svojtka, M., Anderson, K.B., Belete, K.H., Bussert, R., Dörfelt, H., Jancke, S., Mohr, B., Mohrmann, E., Nascimbene, P.C., Nel, A., Nel, P., Ragazzi, E., Roghi, G., Saupe, E.E., Schmidt, K., Schneider, H., Selden, P.A. \& Vávra, N. 2010. 
Cretaceous African life captured in amber. Proceedings of the National Academy of Sciences USA, 107: 7329-7334.

Schmidt, A.R., Jancke, S., Ragazzi, E., Roghi, G., Lindquist, E.E., Nascimbene, P., Schmidt, K., Wappler, T. \& Grimaldi, D.A. 2012. Arthropods in amber from the Triassic Period. Proceedings of the National Academy of Sciences USA, 109: 37: 14796-14801.

Schweigger, A.F. 1819. Beobachtungen auf naturhistorischen Reisen: anatomisch-physiologische Untersuchungen über Corallen ; nebst einem Anhange, Bemerkungen über den Bernstein enthaltend. Berlin: Georg Müller. 127 pp.; pls I-XII.

Scott, A. G. 2003. Sub-fossil spiders from Holocene peat cores. Journal of Arachnology, 31, 1-7.

Scudder, S.H. 1890. The Tertiary insects of North America. Report of the United States Geological Survey 13, 1-734.

Selden, P.A. 1989. Orb-web weaving spiders in the early Cretaceous. Nature, 340: 711-713.

Selden, P.A. 1990. Lower Cretaceous spiders from the Sierra de Montsech, north-east Spain. Palaeontology, 33: 257-285.

Selden, P.A. 1991a. Aranyes del Cretaci inferior de la Serra del Montsec (Espanya). In Les calcàries litogràfiques del Cretaci inferior del Montsec. Deu anys de campanyes paleontològiques (ed. X. Martínez-Delclòs), pp. 77-85. Institut d'Estudis Ilerdencs, Lleida, Spain.

Selden, P.A. 1991b. Lower Cretaceous spiders from the Serra del Montsec (Spain). In The Lower Cretaceous lithographic limestones of Montsec. Ten years of paleontological expeditions (ed. X. Martínez-Delclòs), pp. 53-58. Institut d’Estudis Ilerdencs, Lleida, Spain. 
Selden, P. A. 1996a. First fossil mesothele spider, from the Carboniferous of France. Revue Suisse de Zoologie volume hors série 2: 585-596.

Selden, P. A. 1996b. Fossil mesothele spiders. Nature, 379: 498-499.

Selden, P.A. 2001. Eocene spiders from the Isle of Wight with preserved respiratory structures. Palaeontology, 44: 695-729.

Selden, P.A. 2002. Missing links between Argyroneta and Cybaeidae revealed by fossil spiders. Journal of Arachnology, 30: 189-200.

Selden, P.A. 2003. A new tool for fossil preparation. The Geological Curator, 7: 337-339.

Selden, P.A. 2010. A theridiosomatid spider from the Early Cretaceous of Russia. Bulletin of the British Arachnological Society, 15: 69-78.

Selden, P.A. 2012. A redescription of Juraraneus rasnitsyni Eskov, 1984 (Araneae:

Juraraneidae), from the Jurassic of Russia. Bulletin of the British Arachnological Society, $15,315-321$.

Selden, P.A. 2014a. A new spider (Araneae: Haplogynae: Plectreuridae) from the Cretaceous Fossil-Lagerstätte of El Montsec, Spain. Journal of Arachnology, 42, 16-23.

Selden, P.A. 2014b. Spiders (Arachnida: Araneae) from the Insect Limestone (Bembridge Marls, Late Eocene) of the Isle of Wight, southern England. Earth and Environmental Science Transactions of the Royal Society of Edinburgh, 1-8.

Selden, P.A., Anderson, H.M. \& Anderson, J.M. 2009. A review of the fossil record of spiders (Araneae) with special reference to Africa, and description of a new specimen from the Triassic Molteno Formation of South Africa. African Invertebrates 50, 105-116. 
Selden, P.A., Anderson, H.M., Anderson, J.M. \& Fraser, N.C. 1999. The oldest araneomorph spiders, from the Triassic of South Africa and Virginia. Journal of Arachnology 27, 401414.

Selden, P.A. \& Beattie, R.G. 2013 A spider fossil from the Jurassic Talbragar Fossil Fish Bed of New South Wales. Alcheringa, 37, 203-208.

Selden, P.A., Casado, F. da C. \& Mesquita, M.V. 2002. Funnel-web spiders (Araneae: Dipluridae) from the Lower Cretaceous of Brazil. Boletim do $6^{\circ}$ Simpósio sobre o Cretácio do Brasil / 2do Simposio sobre el Cretácico de América del Sur (2002), 89-91.

Selden, P.A., Casado, F. da C. \& Mesquita, M.V. 2006. Mygalomorph spiders (Araneae: Dipluridae) from the Lower Cretaceous Crato Lagerstätte, Araripe Basin, north-east Brazil. Palaeontology 49, 817-826.

Selden, P.A. \& Dunlop, J.A. 2014. The first fossil spider (Araneae: Palpimanoidea) from the Lower Jurassic (Grimmen, Germany). Zootaxa, 3894, 161-168.

Selden, P.A. \& Gall, J.-C. 1992. A Triassic mygalomorph spider from the northern Vosges, France. Palaeontology 35, 211-235.

Selden, P. A. \& Huang, D-Y. 2010. The oldest haplogyne spider (Araneae: Plectreuridae), from the Middle Jurassic of China. Naturwissenschaften 97: 449-459.

Selden, P.A., Huang, D-Y. \& Ren, D. 2008. Palpimanoid spiders from the Jurassic of China. Journal of Arachnology 36, 306-321.

Selden, P.A., Nam, K.-S., Kim, S.H. \& Kim, H.J. 2012. A fossil spider from the Cretaceous of Korea. Journal of Paleontology, 86, 1-6. 
Selden, P.A. \& Penney, D. 2003. Lower Cretaceous spiders (Arthropoda: Arachnida: Araneae) from Spain. Neues Jahrbuch für Geologie und Paläontologie, Monatshefte 2003, 175192.

Selden, P.A. \& Penney, D. 2009. A fossil spider (Araneae: Pisauridae) of Eocene age from Horsefly, British Columbia, Canada. Contributions to Natural History, 12, 1269-1282.

Selden, P.A., Ren, D. \& Shih, C. 2016. Mesozoic cribellate spiders (Araneae: Deinopoidea) from China. Journal of Systematic Palaeontology, 1-26.

Selden, P.A. \& Romano, M. 1983. First Palaeozoic arachnid from Iberia: Aphantomartus areolatus Pocock (basal Stephanian; prov. Leon, N.W. Spain), with remarks on aphantomartid taxonomy. Boletín geológico y minero, 94, 106-112.

Selden, P.A., Shcherbakov, D.E., Dunlop, J.A. \& Eskov, K.Y. 2014. Arachnids from the Carboniferous of Russia and Ukraine, and the Permian of Kazakhstan. Paläontologische Zeitschrift, 88, 297-307.

Selden, P.A., Shear, W.A. \& Bonamo, P.M. 1991. A spider and other arachnids from the Devonian of New York, and reinterpretations of Devonian Araneae. Palaeontology 34, $241-281$.

Selden, P.A., Shear, W.A. \& Sutton, M.A. 2008. Fossil evidence for the origin of spider spinnerets, and a proposed arachnid order. Proceedings of the National Academy of Sciences of the USA 105, 20781-20785.

Selden, P.A., Shih, C.K. \& Ren, D. 2011. A golden orb-weaver spider (Araneae: Nephilidae: Nephila) from the Middle Jurassic of China. Biology Letters, 7, 775-778. 
Selden, P.A., Shih, C. \& Ren, D. 2013. A giant spider from the Jurassic of China reveals greater diversity of the orbicularian stem group. Naturwissenschaften, 100: 1171-1181.

Selden, P.A. \& Wang, Y. 2014. Fossil spiders (Araneae) from the Eocene Green River Formation of Colorado. Arthropoda Selecta, 23: 207-219.

Sendel, N. 1742. Historia succinorum, corpora aliena involventium, et natura opere pictorum et caelatorum, ex Regiis Augustorum cimeliis Dresdae conditis aeri insculptorum conscriptæ a N. Sendel. Leipzig: Gleditsch.

Senefelder, A. 1821. Vollständiges Lehrbuch der Steindruckerei, second edition. Munich: Senefelder.

Serres, P.M.T. de 1828. Note sur les arachnides et les insectes fossiles, et spécialement sur ceux des terrains d'eau douce. Annales des Sciences Naturelles 15: 98-108.

Serres, P.M.T. de 1829. Des Arachnides et des Insectes fossiles, et spécialement de ceux des terrains d'eau douce du basin tertiaire d'Aix. Livre 4. In Géognosie des terrains tertiaires ou tableau des principaux animaux invertébrés des terrains marins tertiaries du midi de la France (ed. P.M.T. de Serres), pp. 206-258. Pomathio-Durville, Montpellier.

Shear, W.A., Selden, P.A., Rolfe, W.D.I., Bonamo, P.M. \& Grierson, J.D. 1987. New terrestrial arachnids from the Devonian of Gilboa, New York (Arachnida: Trigonotarbida). American Museum Novitates, 2901: 1-74.

Sidorchuk, E.A. 2013. A new technique for preparation of small-sized amber samples with application to mites. Pp. 189-201 in: Azar, D., et al. (eds.) Insect evolution in an amberiferous and stone alphabet: Proceedings of the 6th International Congress on Fossil Insects, Arthropods and Amber. Leiden: Brill. 
Sidorchuk, E.A., Schmidt, A.R., Ragazzi, E., Roghi, G. \& Lindquist, E.E. 2014. Plant-feeding mite diversity in Triassic amber (Acari: Tetrapodili). Journal of Systematic Palaeontology, 13: 129-151.

Sonibare, O.O. Agbaje, O.B., Jacob, D.E., Faithfull, J., Hoffmann, T. \& Foley, S.F. 2014. Terpenoid composition and origin of amber from the Cape York Peninsula, Australia. Australian Journal of Earth Sciences, 61: 979-985.

Soriano, C., Archer, M., Azar, D., Creaser, P., Delclòs, X., Godthelp, H., Hand, S., Jones, A., Nel, A., Néraudeau, D., Ortega-Blanco, J., Pérez-de la Fuente, R., Perrichot, V., Saupe, E., Solórzano Kraemer, M. \& Tafforeau, P. 2010. Synchrotron X-ray imaging of inclusions in amber. Comptes Rendus Palevol, 9: 361-368.

Speranza, M., Wierzchos, J., Alonso, J., Bettucci, L., Martín-González, A. \& Ascaso, C. 2010. Traditional and new microscopy techniques applied to the study of microscopic fungi included in amber. Pp. 1135-1145 in: Mendez-Vilas, A. \& Diaz, J. (eds) Microscopy: Science, Technology, Applications and Education. Formatex Research Centre, Spain.

Stankiewicz, B.A., Briggs, D., Michels, R., Collinson, M.E., Flannery, M.B. \& Evershed, R.P. 2000. Alternative origin of aliphatic polymer in kerogen. Geology, 28: 559-562.

Sutton, M., Rahman, I. \& Garwood, R. 2014. Techniques for virtual paleontology (analytical methods in Earth and environmental science). Wiley-Blackwell/John Wiley \& Sons.

Thomas, D.B., Nascimbene, P.C., Dove, C.J., Grimaldi, D.A. \& James, H.F. 2014. Seeking carotenoid pigments in amber-preserved fossil feathers. Scientific Reports, 4: 5226, DOI: $10.1038 /$ srep05226. 
Thorell, T. 1870. On European spiders. [Part 2]. Nova Acta Regiae Societatis Scientiarum Upsaliensis (3)7, 109-242.

Van de Kamp, T., dos Santos Rolo, T., Baumbach, T. \& Krogmann, L. 2014. Scanning the past synchrotron X-ray microtomography of fossil wasps in amber. Entomologie Heute, 26: $151-160$.

Vinther, J. 2015. A guide to the field of palaeo colour. Bioessays, 37: 643-656.

Vitek, N.S, Vinther, J., Schiffbauer, J.D., Briggs, D.E.G. \& Prum, R. O. 2013. Exceptional threedimensional preservation and coloration of an originally iridescent fossil feather from the Middle Eocene Messel Oil Shale. Paläontologische Zeitschrift, 87: 1-11.

Weitschat, W. \& Wichard, W. 2002. Atlas of plants and animals in Baltic amber. Verlag Dr Friedrich Pfiel, Munich, 256 pp.

Wichard, W. \& Grevin, H. 2009. Über Tausendfüßler, spanische Fliegen und Heuschrecken-Zur „Historia Succinorum“ des Nathanael Sendel von 1742. Denisia, 26, 267-294.

Wood, H.M., Matzke, N.J., Gillespie, R.G. \& Griswold, C.E. 2013. Treating fossils as terminal taxa in divergence time estimation reveals ancient vicariance patterns in the palpimanoid spiders. Systematic Biology, 62, 264-284.

World Spider Catalog 2016: World spider catalog, version 17.0. Bern: Natural History Museum, online at http://wsc.nmbe.ch

Wunderlich, J. 1985. Ein bisher unbekannte fossile Krabbenspinne aus dem Randecker Maar in Südwest-Deutschland (Arachnida: Araneae: Thomisidae). Neue Entomologische Nachrichten 14, 4-13. 
Wunderlich, J. 1986. Die ersten Spinnen aus dem Mittel-Eozän der Grube Messel.

Senckenbergiana lethaea $67,171-176$.

Wunderlich, J. 1988. Die fossilen Spinnen im Dominikanischen Bernstein. Beiträge zur Araneologie 2, 1-380.

Wunderlich, J. 2004. Fossil spiders in amber and copal. Beiträge zur Araneologie, 3: 1-1908.

Wunderlich, J. 2008. Fossil and extant spiders (Araneae). Beiträge zur Araneologie 5, 1-870.

Wunderlich, J. 2015. Mesozoic spiders. Beiträge zur Araneologie, 9: 1-512.

Zhang, J., Sun, B. \& Zhang, X. 1994. Miocene insects and spiders from Shanwang, Shandong. Science Press, Beijing. 298 pp. [In Chinese with English Summary].

Zherikhin, V.V. \& Eskov, K.Y. 1999. Mesozoic and Lower Tertiary resins in former USSR. Estudios del Museo de Ciencias Naturales de Álava, 14(Numero Especiale 2): 119-13

\section{FIGURE LEGENDS}

Fig. 1. Undescribed palpimanid spider (University of Kansas Museum of Natural History, KUMIP 374705) from the Crato Formation (Early Cretaceous, late Aptian), from Nova Olinda, Cearà Province, Brazil, showing three-dimensional preservation by replacement with goethite, typical of spiders from this formation. A synchrotron scan of this specimen is shown in Fig. 16. Scale bar $=1 \mathrm{~mm}$.

Fig. 2. Early drawings of fossil spiders. (A) Plate XII of Kundmann (1737) depicting a spider in an amber pendant (labelled 13) and Spinnensteine on a slab of Solnhofen Limestone (14) - in this case the planktonic crinoid Saccocoma. (B) Plate 11 from Scudder (1890) illustrating spiders form the Eocene of Florissant, Colorado. 
Fig. 3. Holotype of 'Theridium' bucklandii Thorell, 1870 (Natural History Museum, London, BMNH In 43302), Miocene shales of Oeningen, Switzerland, first figured by Buckland (1837, pl. 46, fig. 12). Scale bar $=5 \mathrm{~mm}$.

Fig. 4. Graph showing number of fossil spider species described each year from 1800 to the present day $(\circ)$, and cumulative curve (colour). Peaks above 50 species per year corresponding to important monographs: 1) Koch \& Berendt (1854; Baltic amber), 2) Petrunkevitch (1942; Baltic amber), 3) Wunderlich (1988; Dominican amber); 4) Wunderlich (2004; various ambers), 5) Wunderlich (2008; Baltic amber), 6) Wunderlich (2015; Burmese amber). Data from Dunlop et al. (2016).

Fig. 5. Photographic techniques for imaging fossil spiders. (A) Typical macrophotography setup, with a digital single-lens reflex (DSLR) camera with a macro lens mounted on a macrophotography slider attached to a copy stand. In this example, illumination is provided by four daylight bulbs which can be moved to provide low- or high-angle illumination. Images can be captured using the laptop set-up shown in (B), with the added advantage of automatic capture of z-stacks by stepping the focus of the macro lens using software. (B) Typical set-up for photomicrography. In this example, a digital single-lens reflex (DSLR) camera is mounted on a stereomicroscope by means of a phototube. Incident illumination is provided by twin swan-neck light guides from a halogen light source. The camera is connected by a USB cable to a laptop computer running digital capture software, where adjustments such as ISO, colour temperature, etc, can be made. A live view of the specimen is seen on the screen, so the focus can be checked before image capture, and manual z-stacks can be made. The eyepieces should be covered to prevent the ingress of light, unless the phototube is isolated from the visual light path. 
Fig. 6. High magnification of flattened specimens mounted on glass slides, photographed in transmitted light using Nomarski differential interference contrast microscopy. (A) Fragment of opisthosoma of the uraraneid Attercopus fimbriunguis (Shear, Selden \& Rolfe, 1987) (American Museum of Natural History, SM1.11.4) from the Devonian of South Mountain, New York (see Selden et al., 2008, fig 1C), showing setae and their sockets (a), slit sensilla (b), and silkproducing spigots (c). (B) Tip of tarsus of Attercopus fimbriunguis (American Museum of Natural History, SM1.11.5), showing paired claws (p) and single median claw (m), both fimbriated. Scale bars $=50 \mu \mathrm{m}$.

Fig. 7. High magnification of matrix-preserved specimen using reflected light microscopy and oil-immersion lens. Cretaraneus vilaltae Selden, 1990, holotype (Institut d'Estudis Ilerdencs, Lleida, Spain, LC 1150 IEI), from the early Cretaceous of El Montsec, Spain (see Selden 1989, fig. 4a, 1990, text-fig. 4a). Distal end of tarsus showing pectinate paired claws (p), small, smooth, median claw (m), and fimbriate accessory claws (modified macrosetae) (a). Note that zstacking was not possible during the days of film photography, hence only a small part of the specimen is in focus. Scale bar $=50 \mu \mathrm{m}$.

Fig. 8. Photomicrographs of spider fossils in amber. (A) Eustaloides setosus Petrunkevitch, 1942 in Eocene Baltic amber, showing how light reflection of the curved amber surface causes problems when photographed in air, which can be overcome by immersing the specimen in a fluid with a similar refractive index to the amber (see B). B. Example of an extant orb-web weaving spider Hypognatha testudinaria (Taczanowski, 1879) in copal from Colombia. Specimen photographed under oil, with image produced using photo-stacking software. (C) Photomicrograph of the pedipalps of Mastigusa bitterfeldensis Wunderlich, 2004 in Eocene 
Baltic amber, processed with image-stacking software to enhance the depth of field. (D). Photomicrograph of the pedipalps of Furcembolus andersoni Wunderlich, 2008 in Cretaceous Burmese amber, showing how image-stacking software can be used to produce excellent images of important diagnostic features. (E) Photomicrograph of the pedipalps of Archaea paradoxa Koch \& Berendt, 1854 in Eocene Baltic amber, showing how image stacking software can enhance images of minute features, such as the individual peg-teeth along the chelicerae. Fig. 9. Example of using stacked images to increase depth of field in a rock-matrix preserved specimen: undescribed palpimanoid spider from the Middle Jurassic Jiulongshan Formation, Daohugou, Inner Mongolia, China. Detail of fang and peg-teeth of left chelicera. (A) Edge of fang in focus. (B) Lower left and central part in focus. (C) Lower right part in focus. (D) Merged images showing specimen entirely in focus. See Selden et al. (2008). Scale bar $=0.25 \mathrm{~mm}$. Fig. 10. Eoplectreurys gertschi Selden \& Huang, 2010, Middle Jurassic Jiulongshan Formation, Daohugou, Inner Mongolia, China. (A) Holotype part (Nanjing Institute of Geology and Palaeontology, NIGP151720a), whole specimen showing mainly ventral structures, box shows area of detail shown in B. (B) Detail from A, of tibia 1, with clasper formed from fused macrosetae, and tip of embolus of male pedipalp. (C) Composite of holotype part and counterpart (Nanjing Institute of Geology and Palaeontology, NIGP151720a,b), detail of tibia 1 and embolus of male pedipalp; arrow points to helical distal part of embolus revealed by this process. Scale bar $=1 \mathrm{~mm}$.

Fig. 11. Zhizhu daohugouensis Selden et al., 2016, Middle Jurassic Jiulongshan Formation, Daohugou, Inner Mongolia, China, showing how SEM can extract detailed information form fossil spiders. (A-C) Holotype male part (Capital Normal University, Beijing, CNU-SPI- 
NN2002030-P). (A) Light photomicrograph, taken under alcohol and cross-polarized light, of left leg 4 distal metatarsus and tarsus, showing setae, macrosetae (whorl at mt ta joint), and tarsal claws. (B) SEM detail of leg setae. (C) SEM detail of leg macroseta. (D-G) Paratype female (Capital Normal University, Beijing, CNU-SPI-NN2013002). (D) SEM detail of leg seta and macroseta. (E) higher magnification of same seta and macroseta as in $\mathrm{D}$, showing microstructure seen on external mould and internal fill. (F) EDX elemental mapping of leg macroseta showing distribution of Si, Al, O, K and C. (G) Distributions of separate elements across same area as in $\mathrm{F}$; note the concentration of $\mathrm{C}$ along macroseta, other elements in matrix, shown by $\mathrm{F}$ and $\mathrm{G}$. Scale bars: A $=0.5 \mathrm{~mm} ; \mathrm{B}-\mathrm{C}, \mathrm{F}-\mathrm{G}=0.5 \mu \mathrm{m} ; \mathrm{D}=40 \mu \mathrm{m} ; \mathrm{E}=10 \mu \mathrm{m}$.

Fig. 12. X-ray computed tomography (CT scanning) of fossil spiders preserved in amber. (A) Three-dimensional reconstruction, based on CT scan, of Balticoroma wheateri Penney \& Marusik, 2011 (in Penney et al., 2011) in Eocene Baltic amber, viewed from multiple angles. Note the different reconstructions of left and right pedipalp, despite both appearing equally well preserved under the light microscope. Scale bar $=1 \mathrm{~mm}$. (B) Anterior view 3D CT reconstruction (left) and a raw data slice (right) from the CT scan of Balticoroma wheateri. Again, note the different reconstruction of left and right pedipalp, despite both appearing equally well preserved under the light microscope. The data slice was examined to determine whether the unusual cheliceral extensions (ce) were attached to the ectal surface of the chelicerae (c) or whether they were downward projections of the carapace, confirming the latter.

Fig. 13. Examples of the use of $\mathrm{CT}$ scanning to view the internal anatomy of fossil spiders preserved in amber, revealing details that would be hidden using traditional microscopy. (A) Lateral view 3D CT reconstruction (left) and section (right) from a CT scan of Cenotextricella 
simoni Penney, 2007 (in Penney et al., 2007) in Eocene Paris amber. Scale bar $=1 \mathrm{~mm}$. (B-G) Craspedisia yapchoontecki Penney \& Marusik, 2012 (in Penney et al., 2012) in Miocene Dominican amber, B-F holotype (Natural History Museum, London, NHM IA186), G paratype SMF, no. 39004. (B) CT reconstruction, lateral view, 4× optical magnification. (C) CT reconstruction, section, lateral view; $4 \times$ optical magnification. (D) CT reconstruction, ventral view, $4 \times$ optical magnification. (E) Detail of clypeal region showing eyes and clypeal projection, $20 \times$ optical magnification. (F) Photomicrograph of holotype specimen; inset: pedipalp showing curved embolus. (G) Photomicrograph of paratype specimen. Scale bars $=1.0 \mathrm{~mm}$.

Fig. 14. Advanced techniques of CT scanning of fossil spiders in amber. (A) Legs of a pirate spider (American Museum of Natural History, AMNH Tad-52) in Eocene Indian amber reconstructed using semi-automatic segmentation of the CT scan data, extracted using narrow thresholds tuned to both the dark fringe (green) and bright fringe (purple), which enables the characteristic leg spines to be visualized with the minimum number of artefacts (after McNeil et al., 2010). Specimen described but not named by Penney et al. (2012b). Scale bar $=10 \mu \mathrm{m}$. (B) CT scan reconstruction of the chelicerae and fangs of Eusparassus crassipes (Koch \& Berendt, 1854), lectotype (Museum für Naturkunde, Berlin, MfN MB.A.1604), in Eocene Baltic amber, showing how computed tomography can be used to recover data from historical amber that has degraded to the point that it is no longer possible to study thoroughly using traditional light microscopy. This image also shows the remarkable resolution that can be achieved using labbased CT methods (after Dunlop et al., 2011). Scale bar $=10 \mu \mathrm{m}$. (C) Amber specimen (arrowed) mounted for scanning in the European Synchrotron Radiation Facility at Grenoble, France. (D) Synchrotron CT reconstruction of the right pedipalp of Orchestina gappi Saupe et al., 2012, 
holotype (Department of Geosciences, University Rennes, France, IGR.ARC-28.2), from the Font-de-Benon quarry, Archingeay-Les Nouillers, Charente-Maritime, France, lateral view (after Saupe et al., 2012, fig. 5). Scale bar $=200 \mu \mathrm{m}$. (E) 3D print of Orchestina sp. 1 (Colección Paleontológica de Teruel, Spain, CPT-4100), from the San Just outcrop, Teruel, Spain (see Soriano et al., 2010, fig. 4, and Saupe et al., 2012, fig. 8).

Fig. 15. Important morphological details for spider identification revealed by high-resolution light microscopy; photomicrographs taken in polarized light with specimens under $70 \%$ ethanol. (A-C) Eocoddingtonia eskovi Selden, 2010, paratype female counterpart, (Palaeontological Institute, Russian Academy of Sciences, Moscow, PIN 4210-5462b), from the Cretaceous Baissa locality of Buryat Autonomous Republic, western Transbaikalia, Russia. (A) Detail of epigyne; see (B) for explanation (from Selden, 2010, fig. 30). (B) Explanatory drawing of (A). (C) Leg II tibia, showing cluster of trichobothria (arrowed); distal to the left. (D-F) Mongolarachne jurassica (Selden et al., 2011), allotopotype male part (Capital Normal University, Beijing, CNU-ARA-NN2011001-1) (from Selden et al., 2013, fig. 2). (D) Right leg 1 tibia showing cuticular structures. (E) Higher magnification of trichobothria of left leg 4, showing crescentic bothrial base; distal to the right. (F) Basal part of left leg 4 metatarsus showing detail of calamistrum and simple setae; distal to the left.

Fig. 16. Synchrotron CT scans of the palpimanid spider from the Crato Formation of Brazil shown in Fig. 1. (A) Still from video showing horizontal slice through specimen deeper than shown in Fig. 1, showing section through anterior, raised area of carapace (car), chelicerae (ch), opisthosoma (op), and legs (11-4). (B-C) 3D reconstructions of the specimen. (B) Dorsal view. 
(C) Ventral view. Beamline 2BM-A, scan resolution 2.75 micron of voxel size, Pointgrey

Grasshopper 3 detector, $100 \mathrm{keV}$ energy beam, $100 \mathrm{~mm}$ propagation distance. Scale bars $=1 \mathrm{~mm}$. 


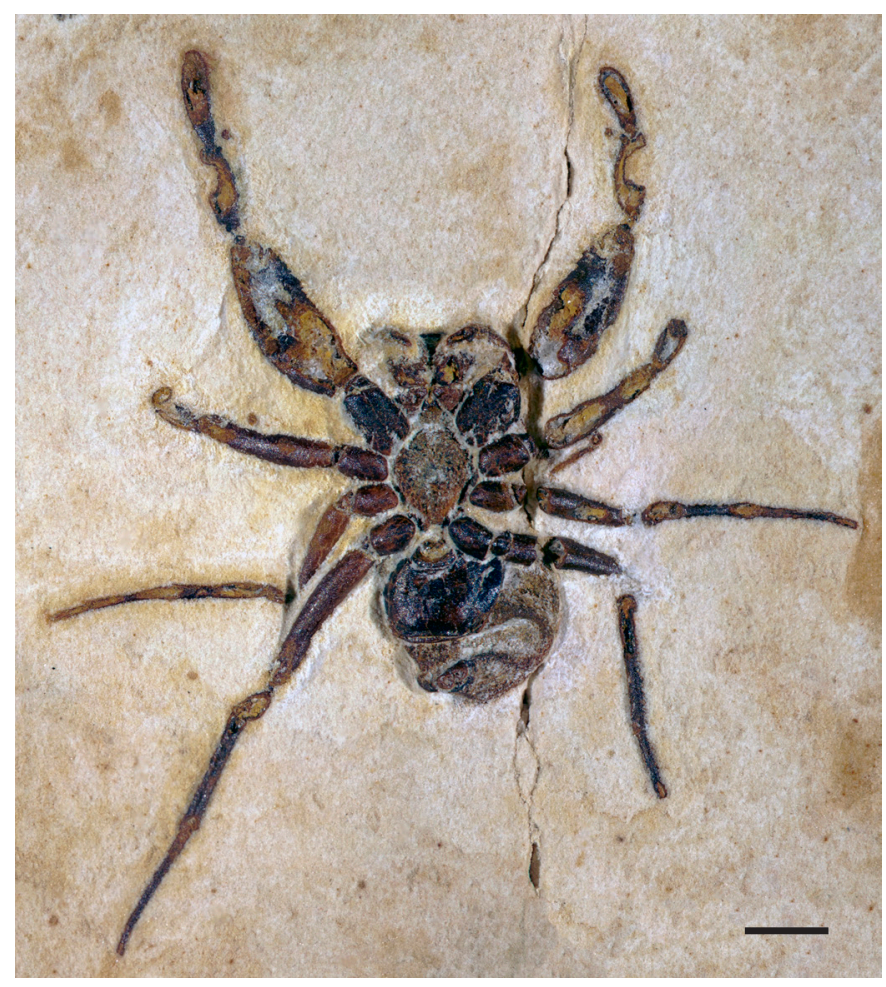

Fig. 1 

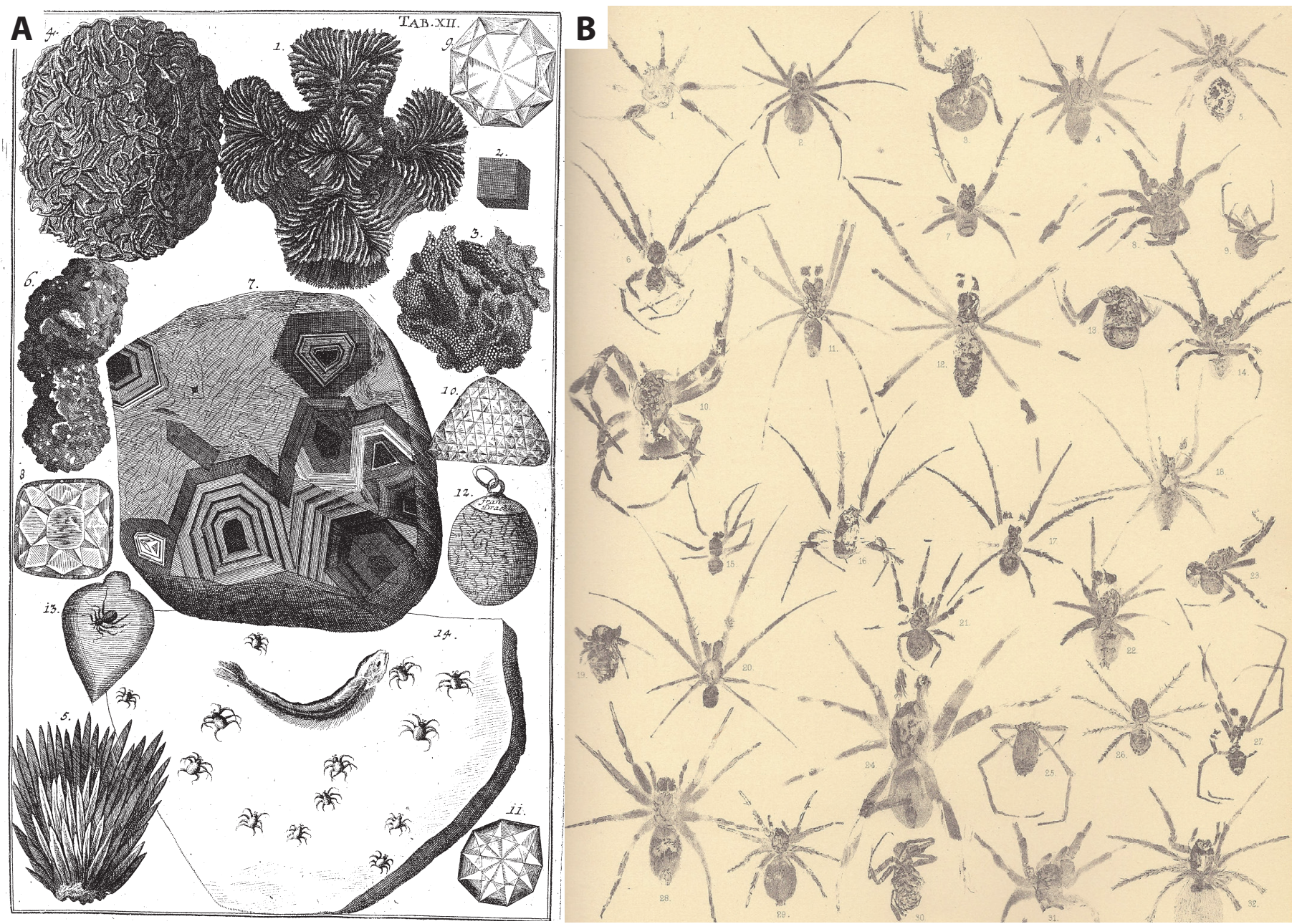

Fig. 2 


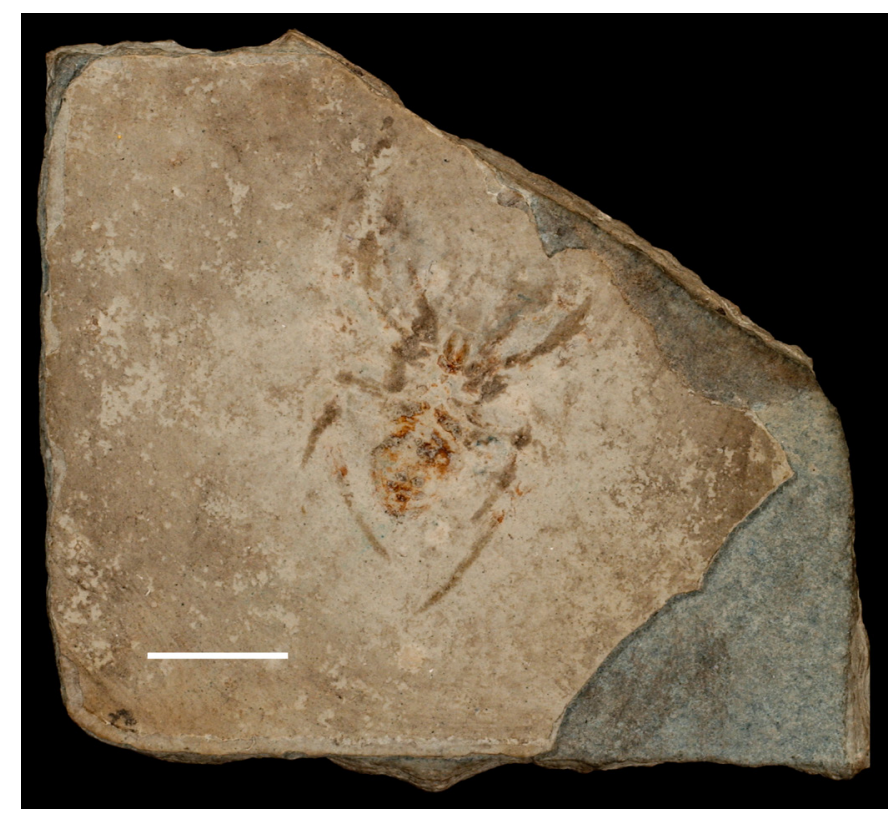

Fig. 3 


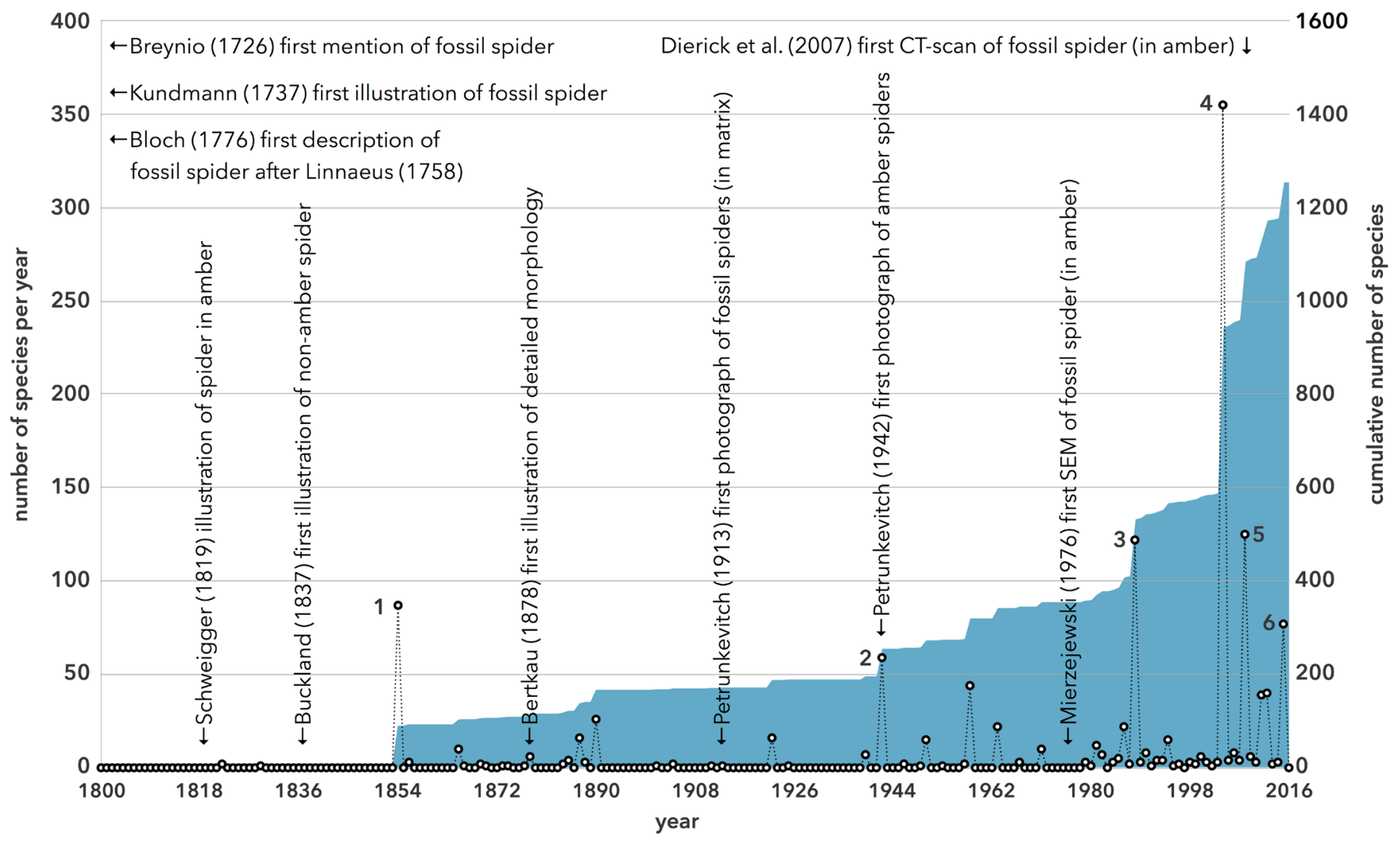

Fig. 4 


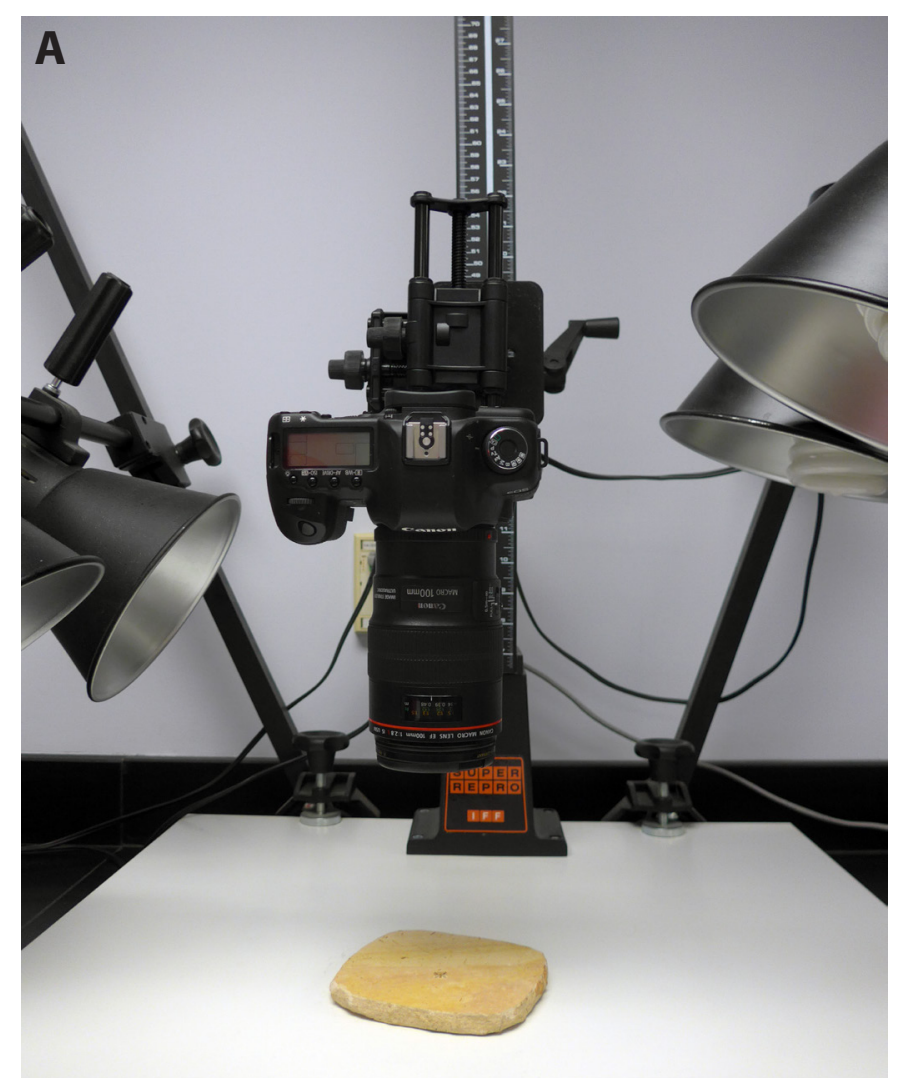

Fig. 5

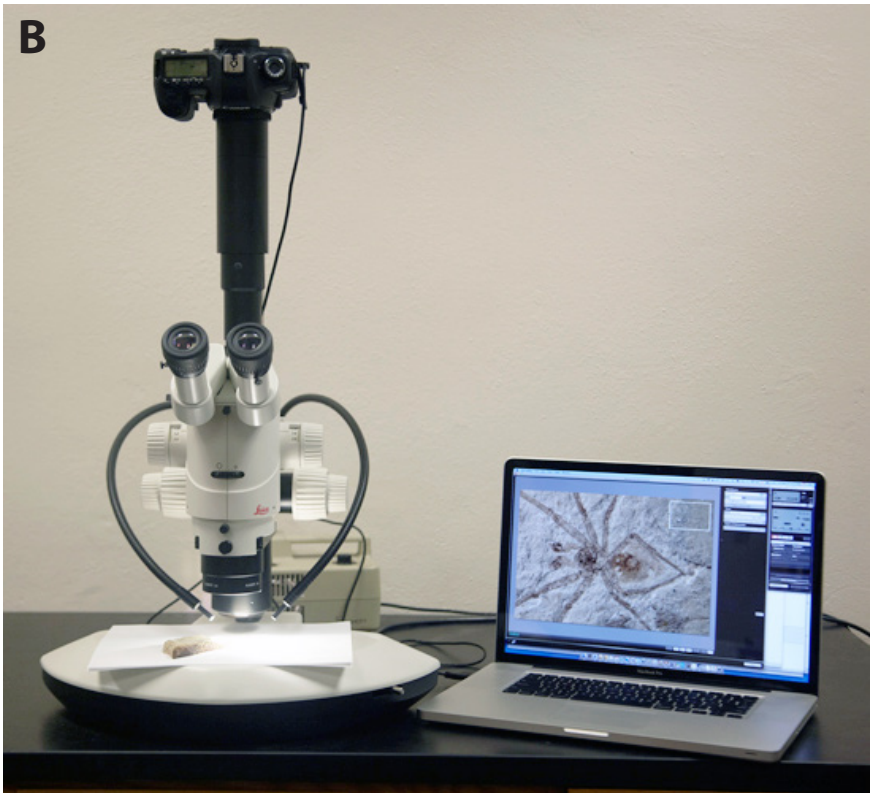




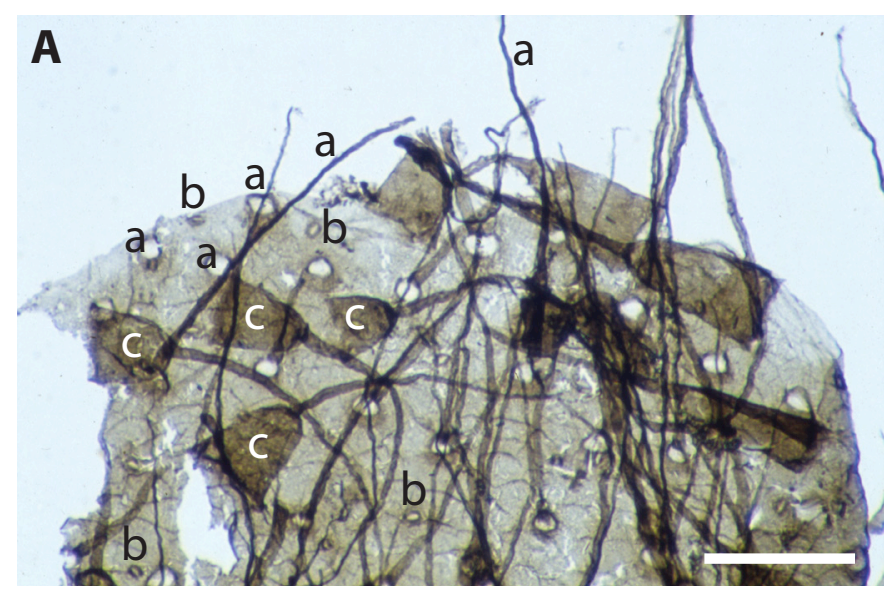

Fig. 6

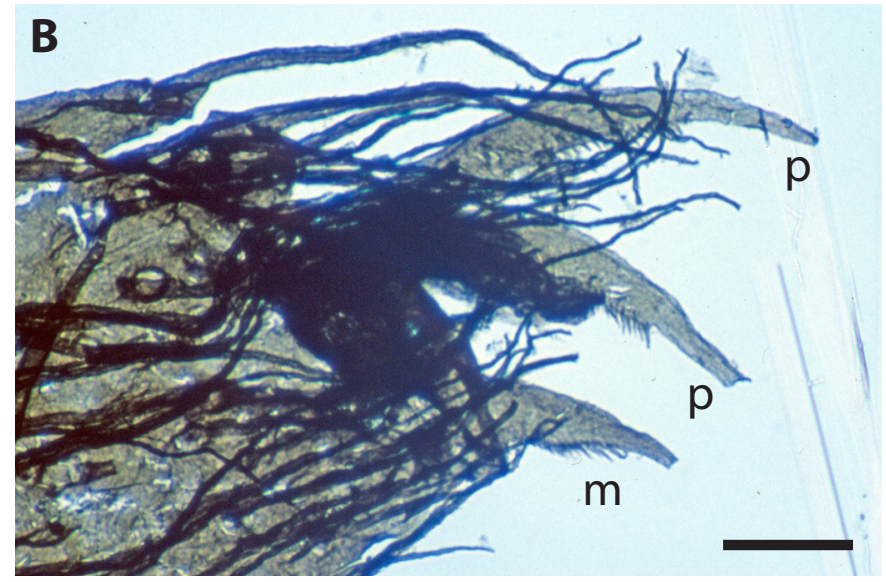




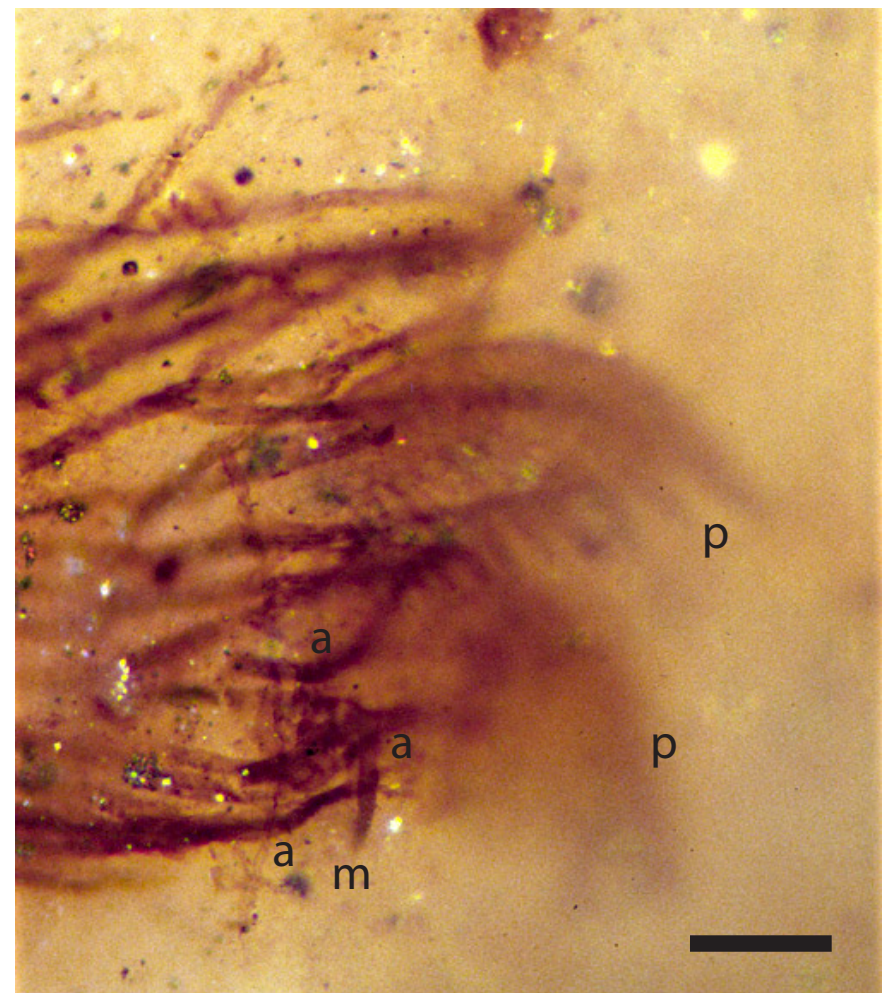

Fig. 7 

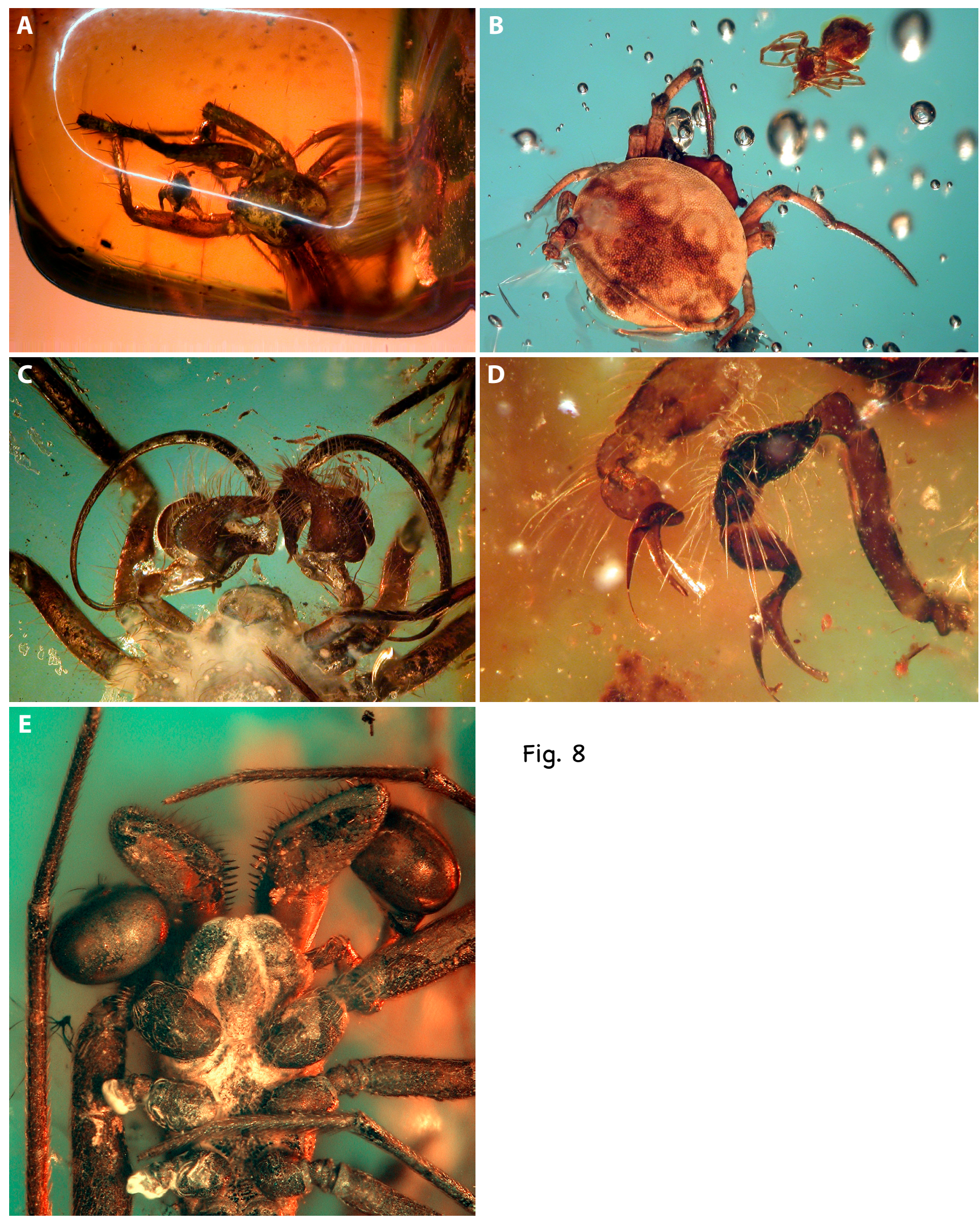

Fig. 8 


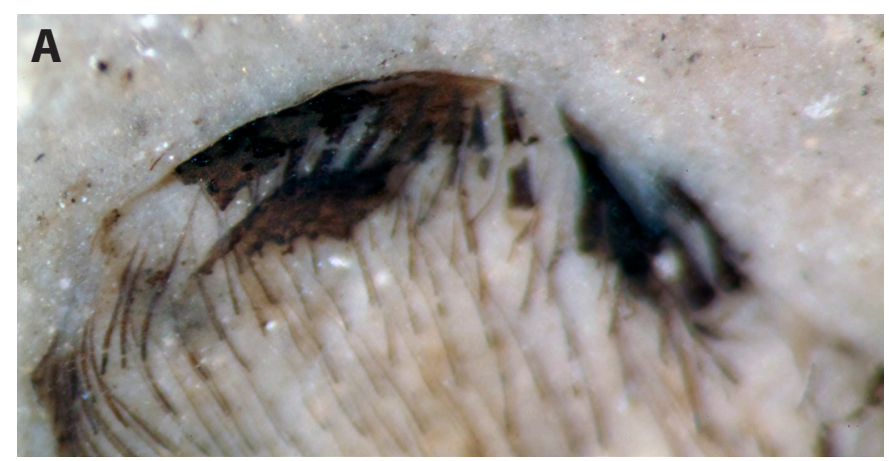

Fig. 9
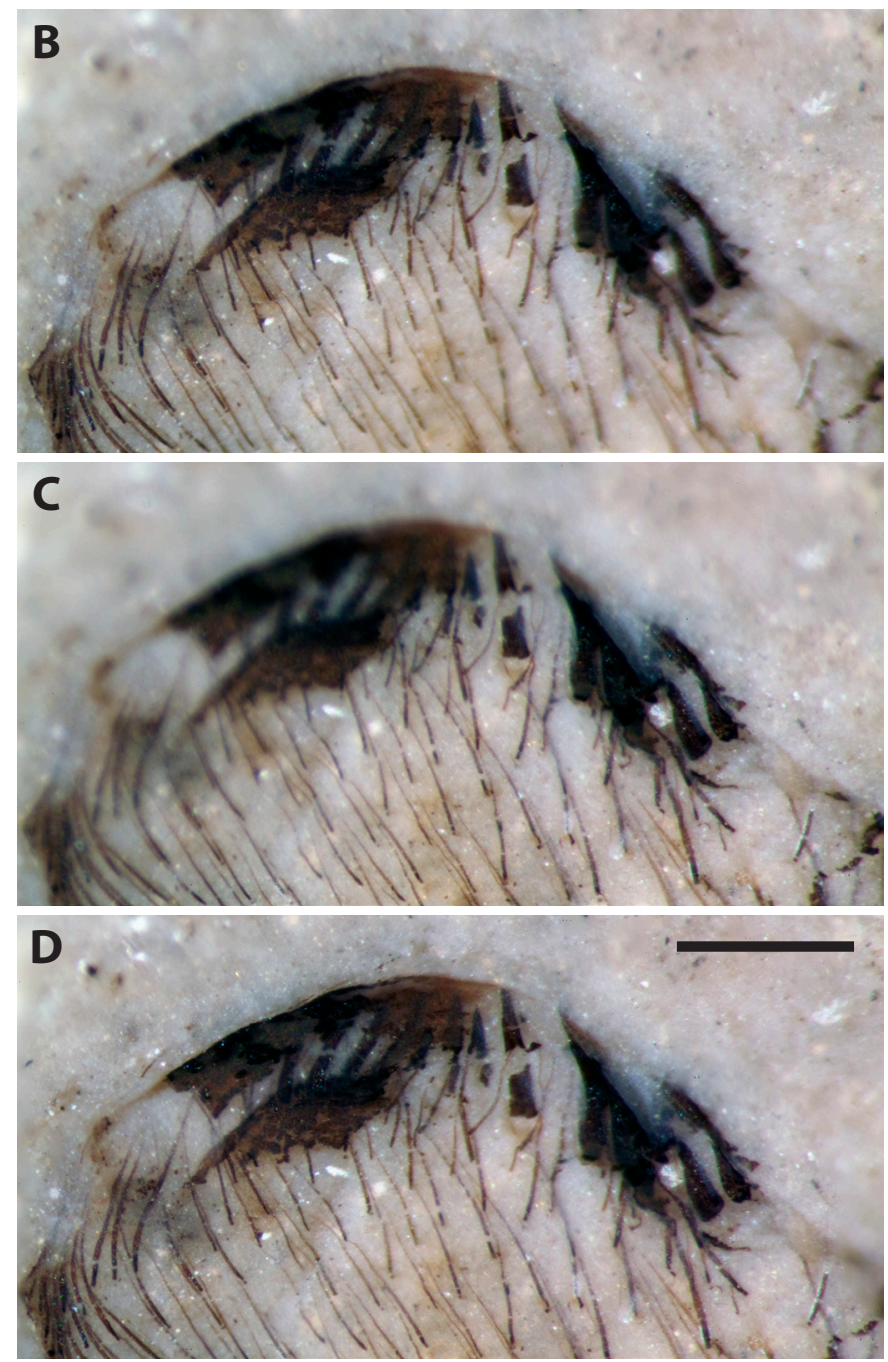


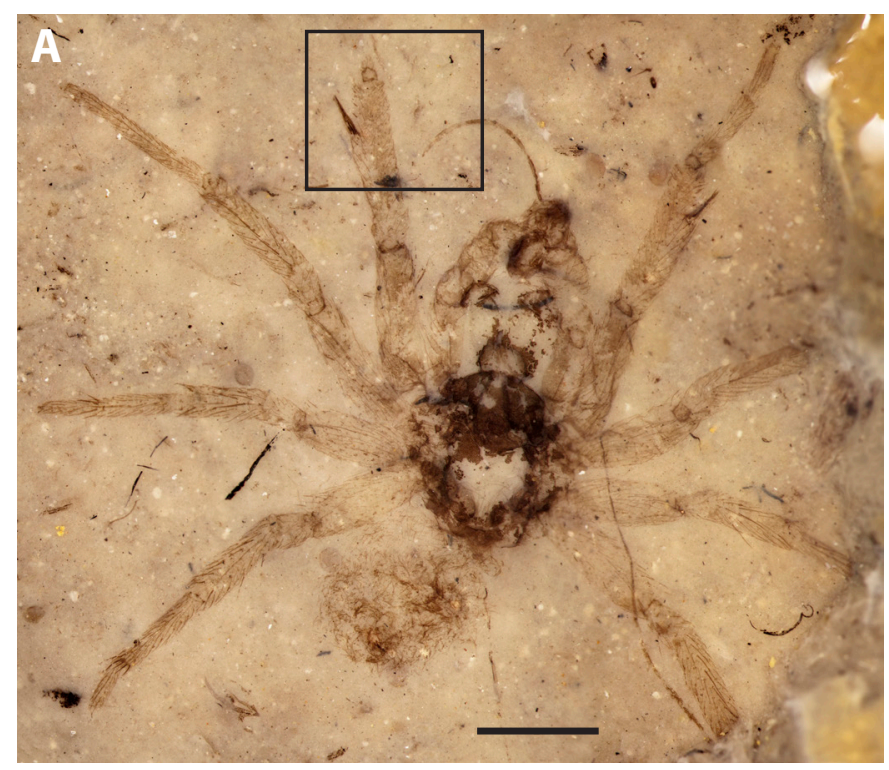

Fig. 10
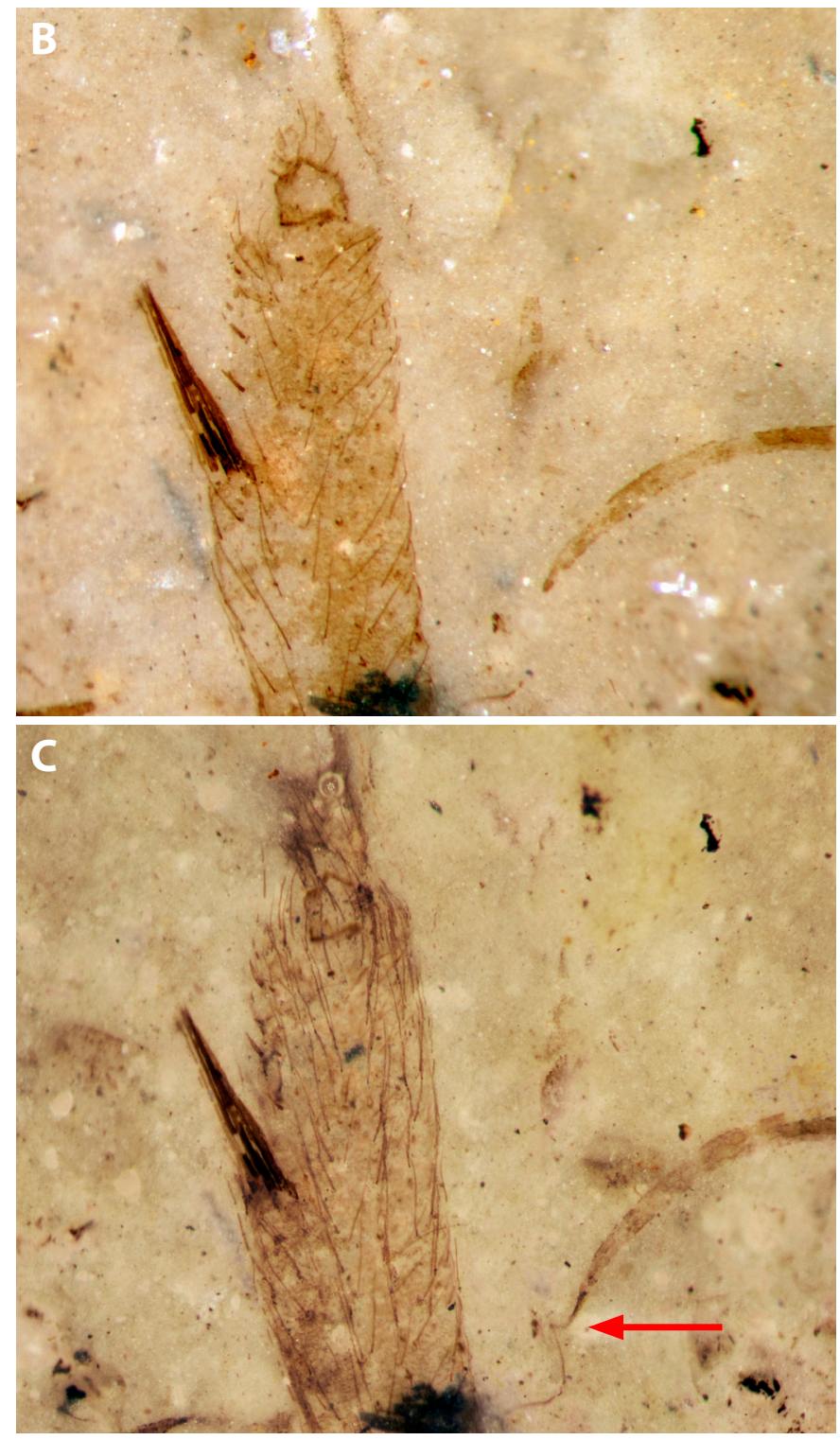

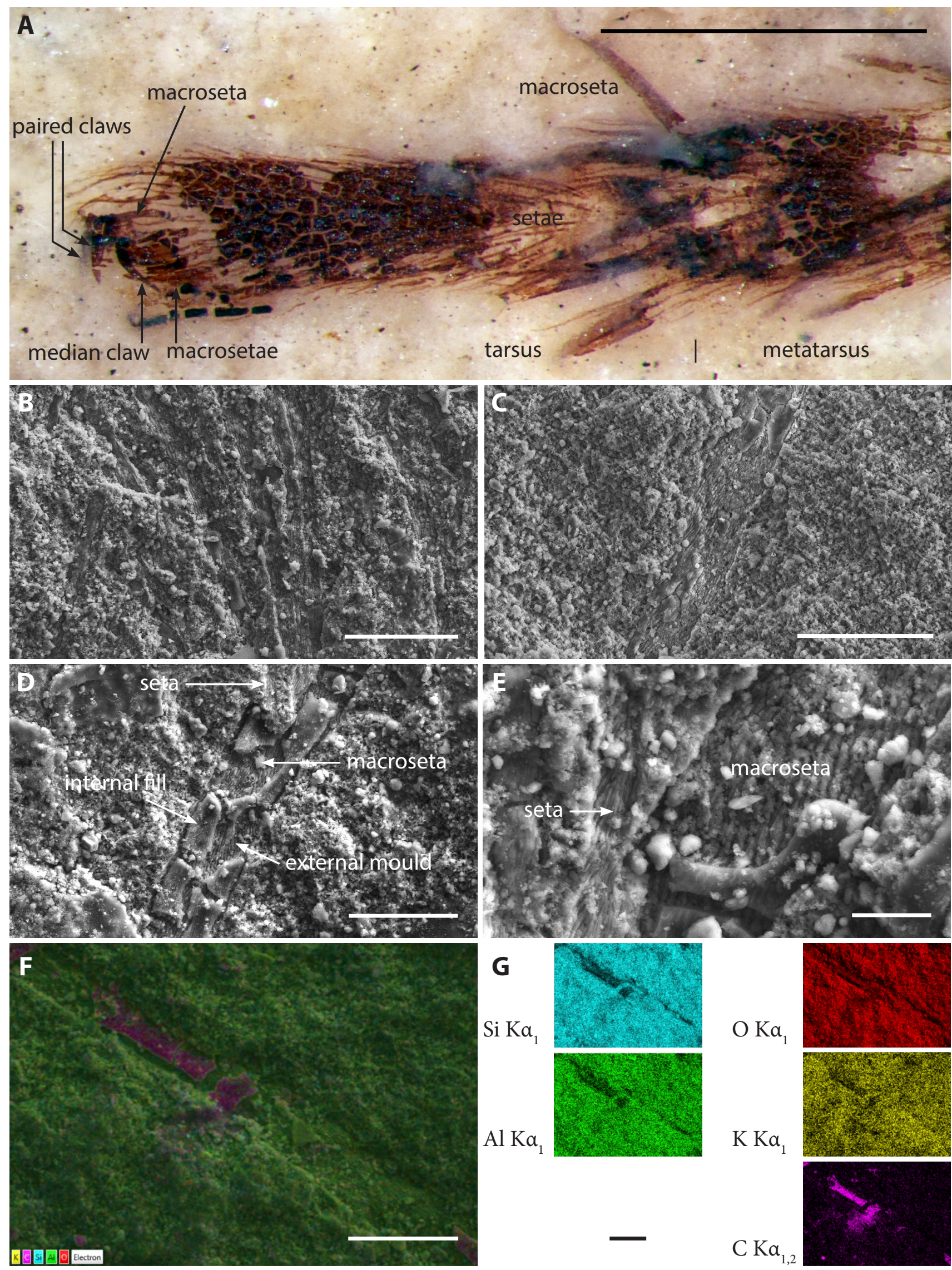

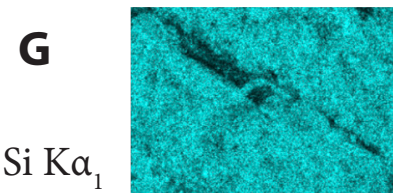

$\mathrm{Al} \mathrm{Ka}$

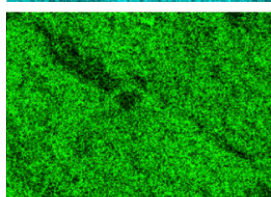

K Ka

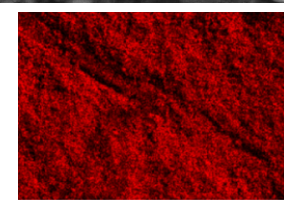

$\mathrm{O} \mathrm{Ka}$
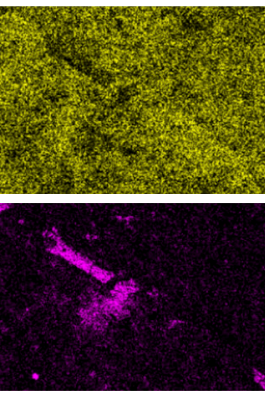

Fig. 11 

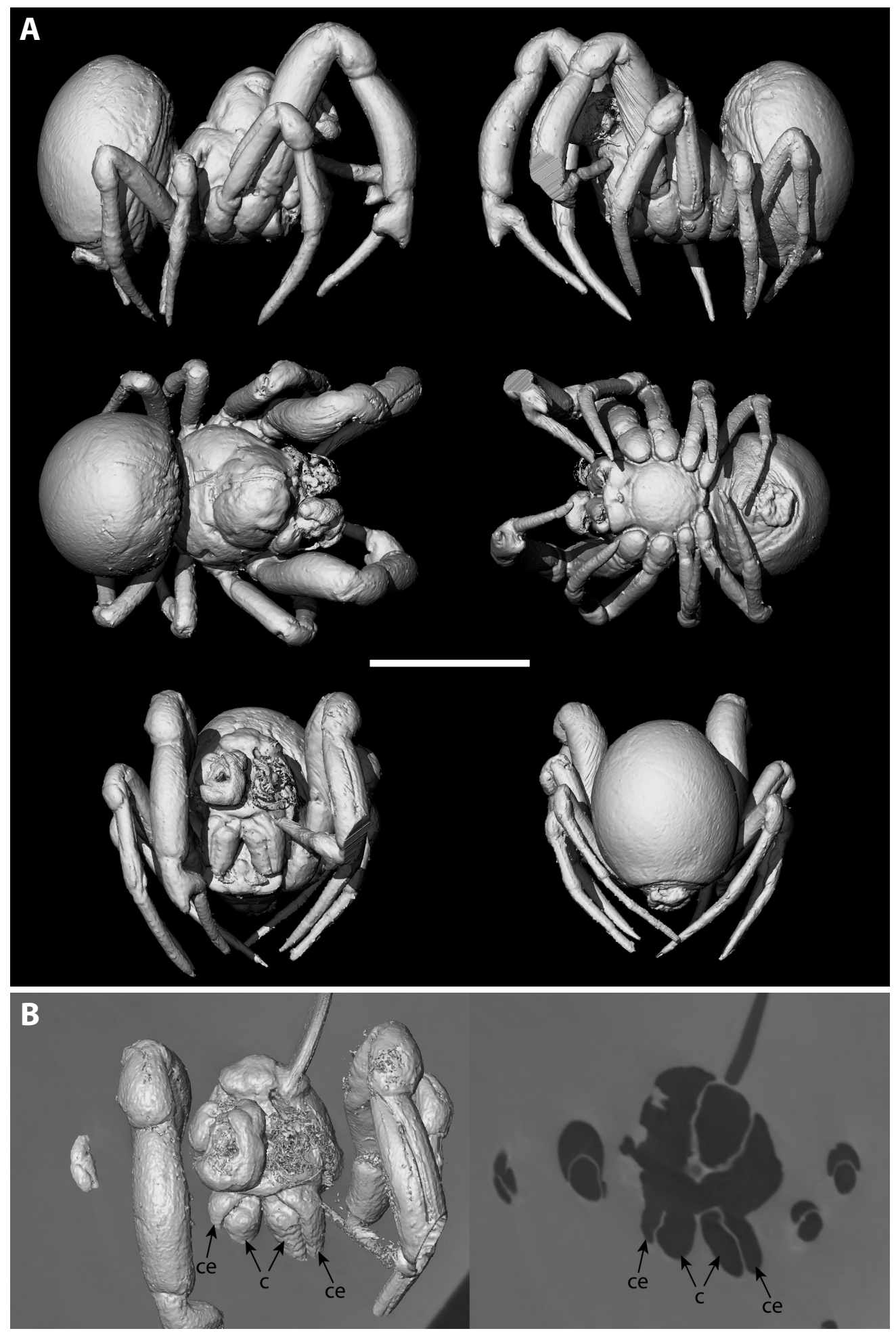

Fig. 12 

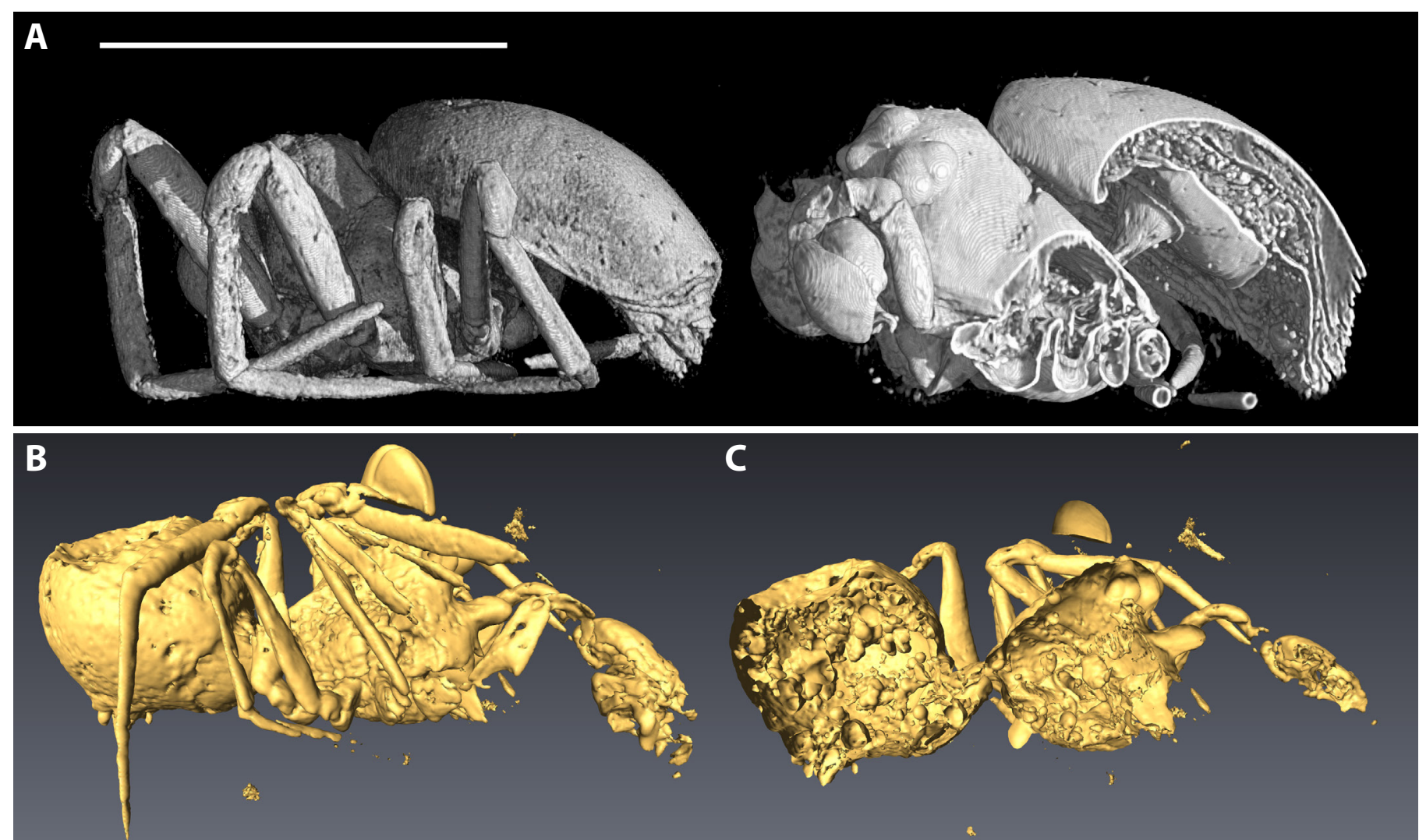

C

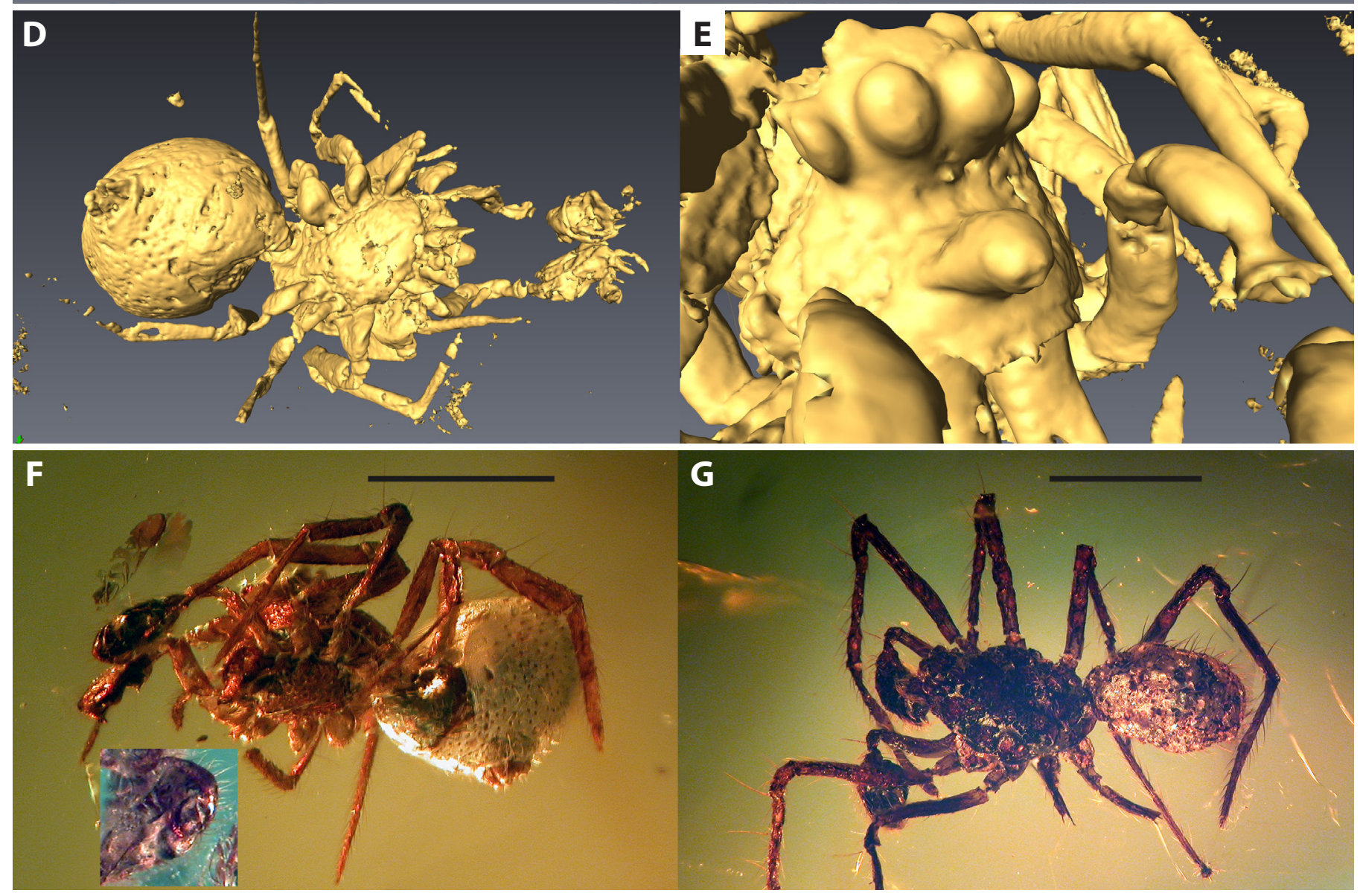

Fig. 13 
A
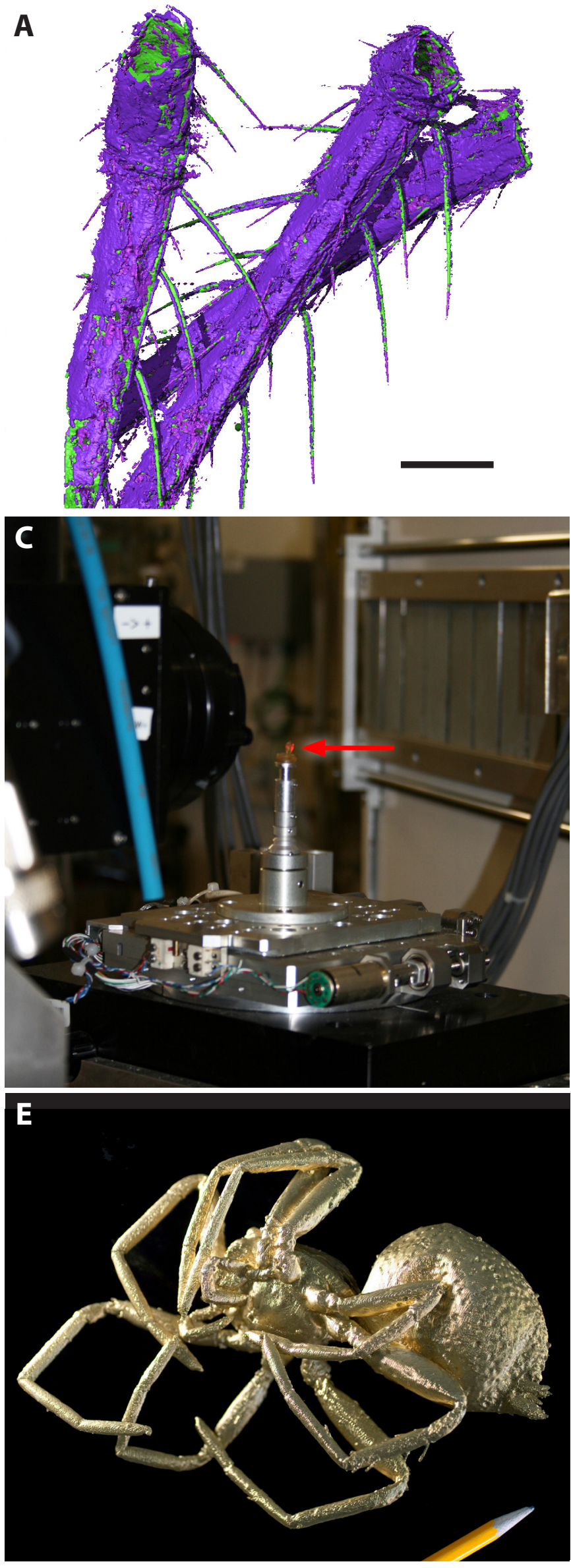
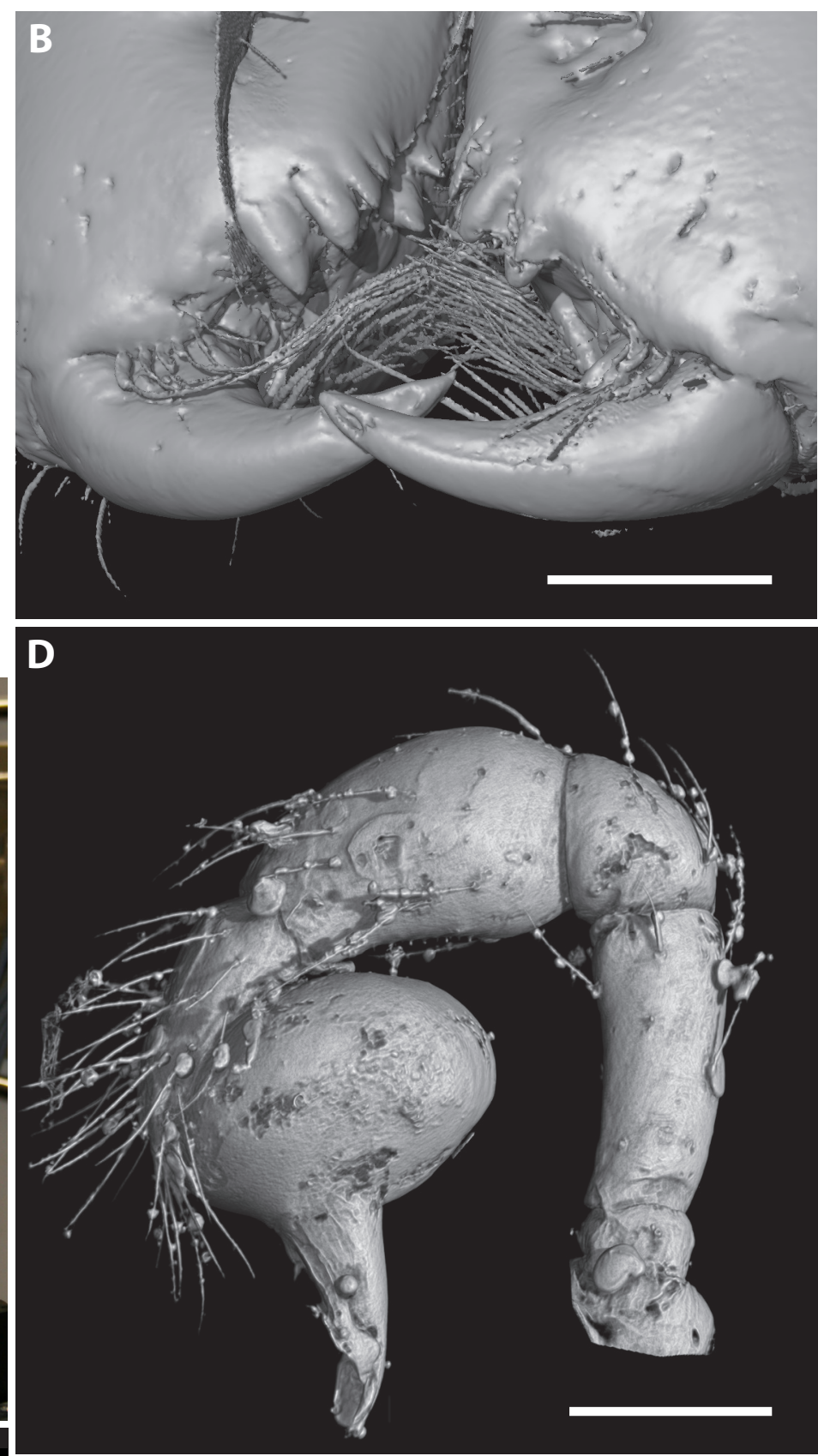

Fig. 14 


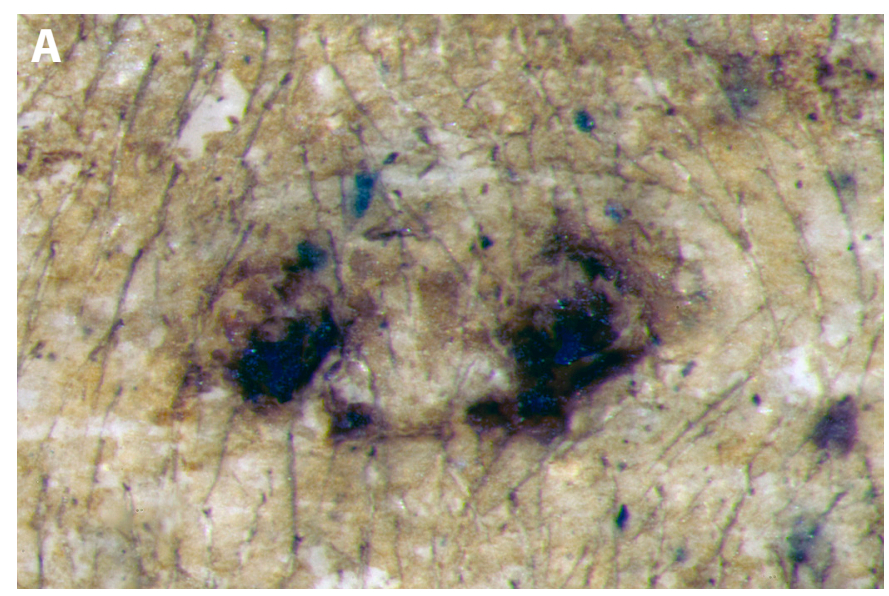

Fig. 15
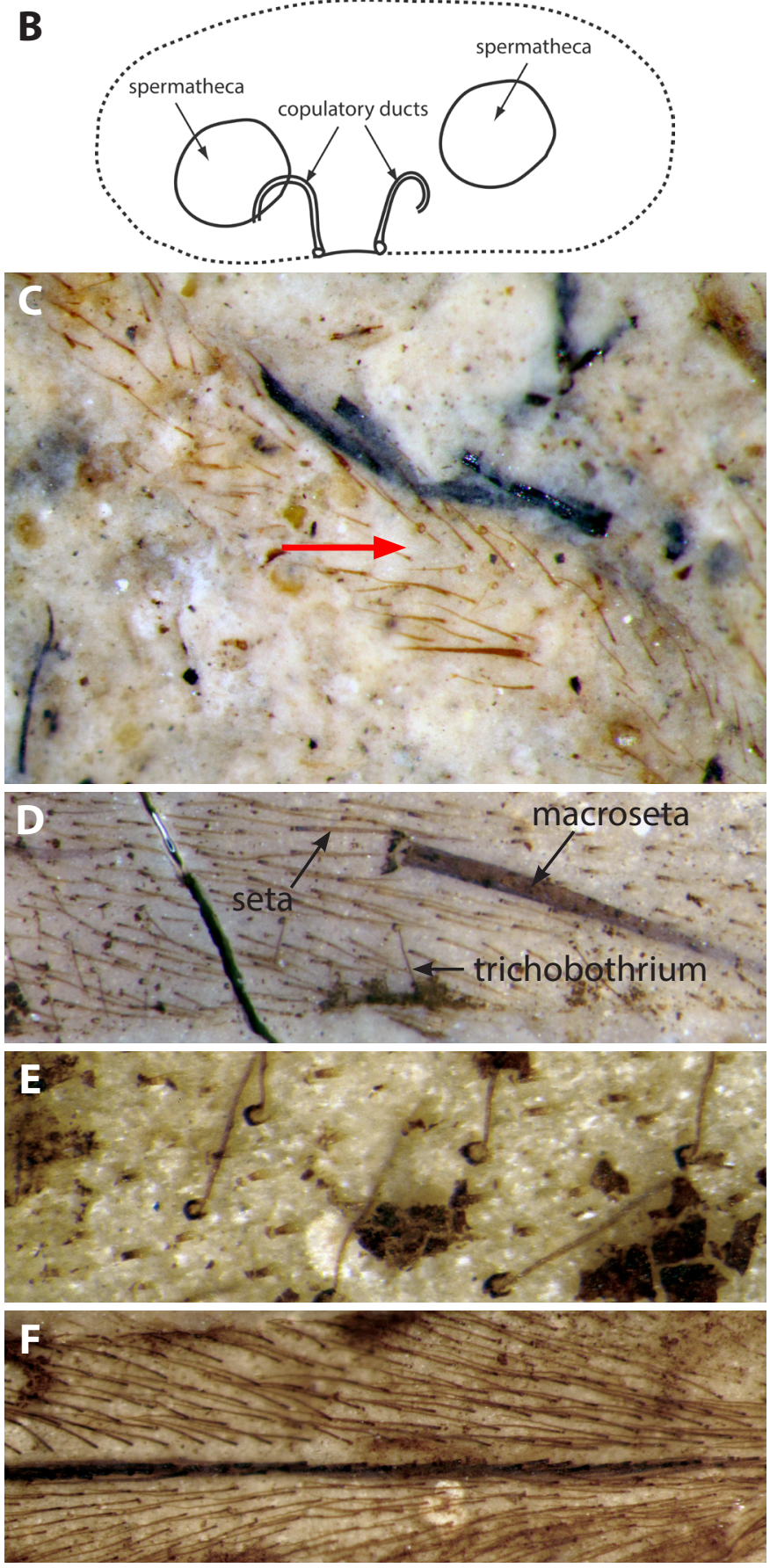


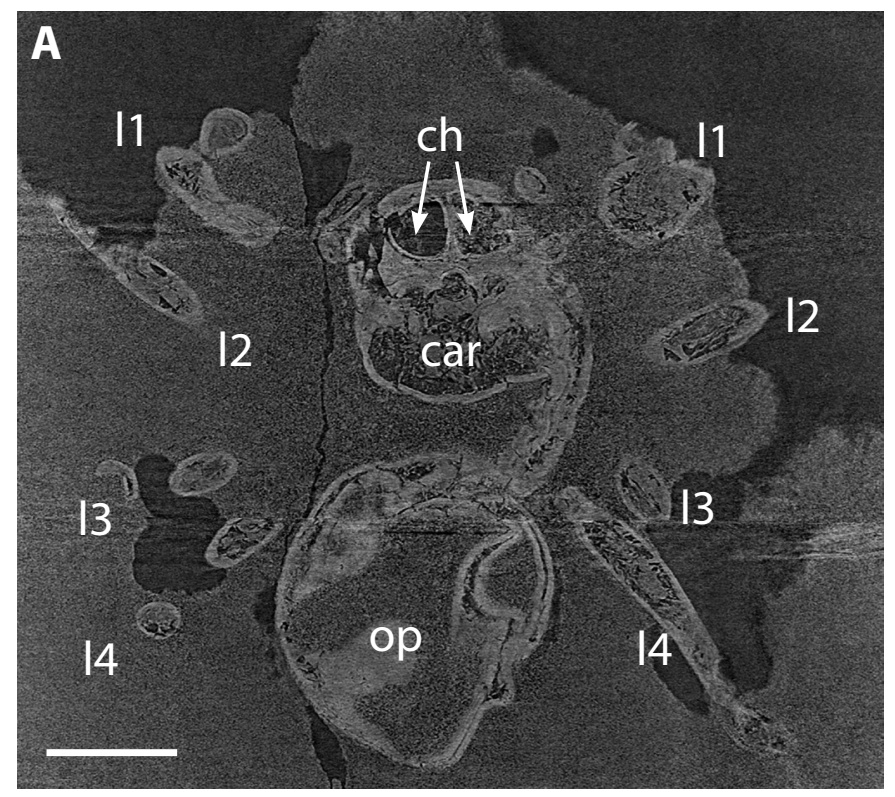

Fig. 16
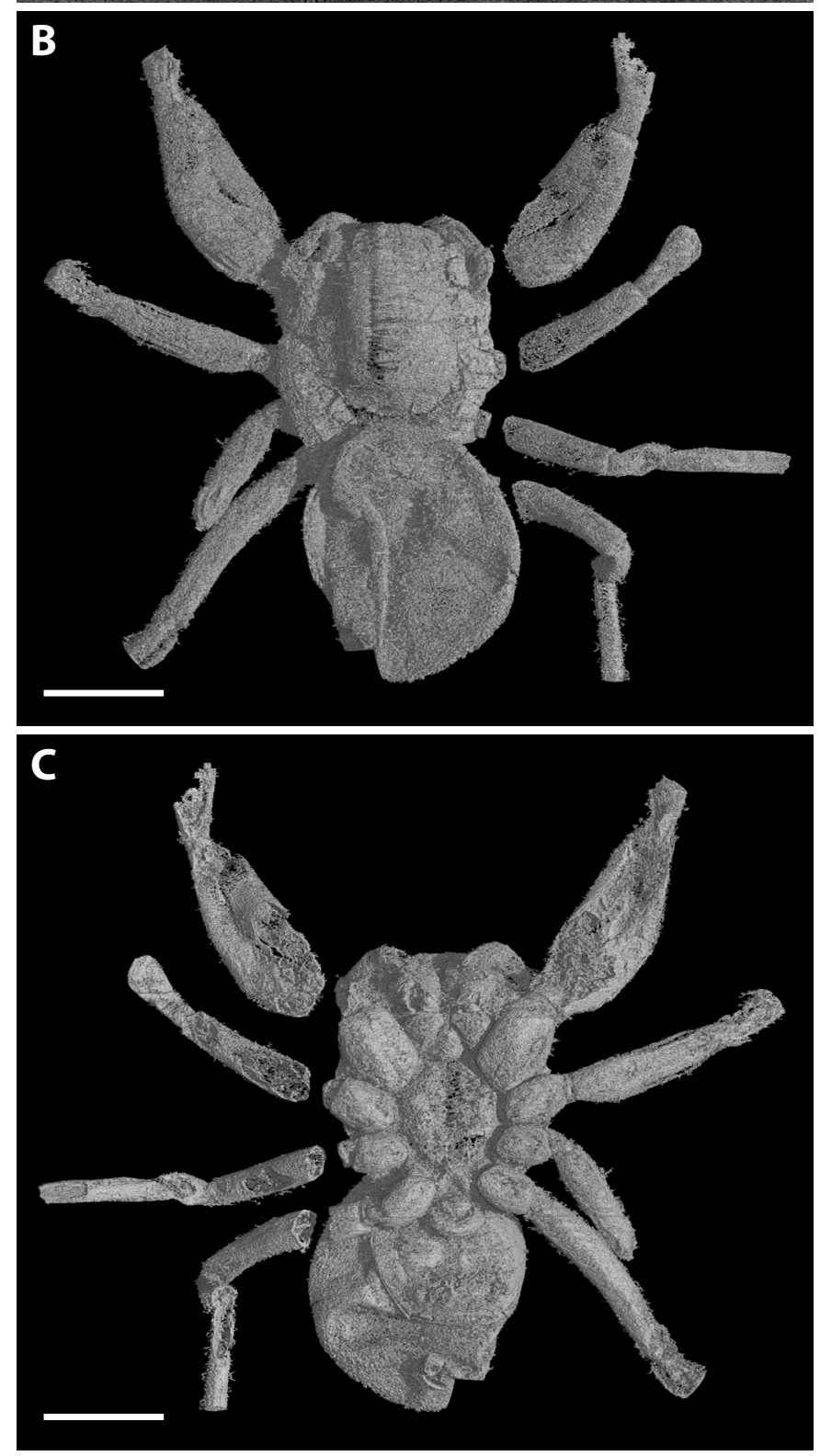